\title{
Mapping Temperature Changes
}

\author{
Xin Qi, Miaoni Gao, Tao Zhu, Siyu Li, Sicheng He, and Jing Yang
}

\section{Introduction}

Under the background of global warming, extreme temperature events have significantly increased and hit various parts of the globe (Alexander et al. 2006; Piao et al. 2010; Fischer and Knutti 2014; Gao et al. 2019; Qi et al. 2019) for example, extreme high temperature occurred during the summer of 2010 over Central Europe-Russia (Grumm 2011) and the super cold surge swept across China at the end of 2020 (Zheng et al. 2021). As a serious worldwide challenge, extreme temperature events bring severe damages to public health, agricultural production, and socioeconomic systems (Easterling et al. 2000; Sun et al. 2018; Wang et al. 2019). Therefore, assessing future global temperature changes is crucial for tackling climate change and disaster mitigation and prevention.

Several studies have attempted to project future changes in temperature at the global scale or with a focus on certain regions through the coarse global climate models (GCMs) or high-resolution regional climate models (Zobel et al. 2017;

Authors: Xin Qi, Miaoni Gao, Tao Zhu, Siyu Li, Sicheng He, Jing Yang.

Map Designers: Tian Liu, Yelin Sun, Fanya Shi, Jing'ai Wang, Ying Wang.

Language Editor: Jing Yang.

X. Qi $\cdot$ T. Zhu $\cdot$ S. Li $\cdot$ S. He $\cdot$ J. Yang $(\bowtie)$

Faculty of Geographical Science, Beijing Normal University,

Beijing, 100875, China

e-mail: yangjing@bnu.edu.cn

J. Yang

State Key Laboratory of Earth Surface Processes and Resource

Ecology, Faculty of Geographical Science, Beijing Normal

University, Beijing, 100875, China

M. Gao

School of Geographical Science, Nanjing University of

Information Science and Technology, Nanjing, 210044, China
Dosio et al. 2018; Nangombe et al. 2018). However, the global temperature changes including the mean state, variance, and extreme temperature in the future based on fine-resolution multiple GCM outputs are rarely reported in the previous literature. A high-resolution $\left(0.25^{\circ} \times 0.25^{\circ}\right)$ dataset named NASA Earth Exchange Global Daily Downscaled Projections (NEX-GDDP) has been released (Thrasher et al. 2012, 2013), which enables the temperature assessment from a global perspective. NEX-GDDP is a statistical downscaling dataset using the bias correction and spatial disaggregation method based on the simulations of the GCMs from the Coupled Model Intercomparison Project Phase 5 (CMIP5) and historical observation (Wood et al. 2004; Maurer et al. 2010). Compared with the original GCM outputs, the historical fidelity of climatology and extreme temperature derived from the downscaled NEX-GDDP has been improved (Bao and Wen 2017; Luo et al. 2020), which provides us a new opportunity to perform a comprehensive assessment of future changes in temperature.

Therefore, this section initiatively investigates the prospective changes in the mean state, variance, and extreme values of global temperature under three greenhouse gas emissions scenarios, including Representative Concentration Pathway (RCP) 2.6, RCP4.5, and RCP8.5, for two target periods (the 2030s and 2050s). The present results provide a fundamental reference for the relevant climate risk identification and assessment. 


\section{Data}

The global daily maximum and minimum temperature for the period from 1950 to 2100 were retrieved from the NEX-GDDP dataset, including downscaled projections from the 21 models under RCP4.5 and RCP8.5 greenhouse gas emissions scenarios for which daily datasets were produced and distributed under CMIP5. The spatial resolution of the data is $0.25^{\circ}(\sim 25 \mathrm{~km} \times 25 \mathrm{~km})$. In addition, the projection with the same resolution for RCP2.6 from the 13 models was assimilated by the Institute of Atmospheric Physics (IAP) and Chinese Academy of Sciences (CAS), which covers the region between $60^{\circ} \mathrm{S}$ and $90^{\circ} \mathrm{N}$ (Xu and Wang 2019). The NEX-GDDP dataset can be freely accessed on the following website: https://www.nccs.nasa.gov/services/ data-collections/land-based-products/nex-gddp.

\section{Method}

Here the temporal range is divided into three periods: the historical period (2000s) defined as 1986-2005, the future period 2030s (2016-2035), and the future period 2050s (2046-2065). Note that summer and winter refer to JuneJuly-August (JJA) and December-January-February (DJF), respectively. Furthermore, the extreme temperature is measured by both an absolute index (TXx) and two percentile indices (TX90p and TN10p) according to the definitions of extremes indices recommended by the Expert Team on Climate Change Detection and Indices (ETCCDI) (Karl and
Easterling 1999; Zhang et al. 2011; Fan et al. 2020). Tmean is defined as the average daily minimum and maximum temperature. Tstd is defined as the standard deviation of the daily mean temperature. $T X x$ refers to the multi-model ensemble of annual maximum near-surface air temperature during the historical period or future time periods based on the NEX-GDDP models. TX90p (TN1Op) refers to the percentage of the days with the daily maximum (minimum) temperature exceeding (below) the local calendar day 90th (10th) percentile centered on a 5-day window for the base period 1961-1990. In addition, The Tmean change is calculated by subtracting the Tmean during the historical period (2000s) from the Tmean under the RCP scenarios in the future. The model uncertainty of the Tmean is represented by the standard deviation of the Tmean under the RCP scenarios during the different periods based on all selected models. Changes and model uncertainties of $T s t d, T X x$, $T X 90 p$, and TN10p are calculated in the same way as Tmean.

\section{Major Findings}

Figure 1 shows the daily Tmean over nine regions under different greenhouse gas emissions scenarios, respectively, for the 2030s and 2050s. Compared to the historical period (gray bar), the nine selected regions in all RCP scenarios are expected to experience warming in the future. Under the same RCP scenarios, Tmean in the 2050s is higher than in the 2030s in all regions.

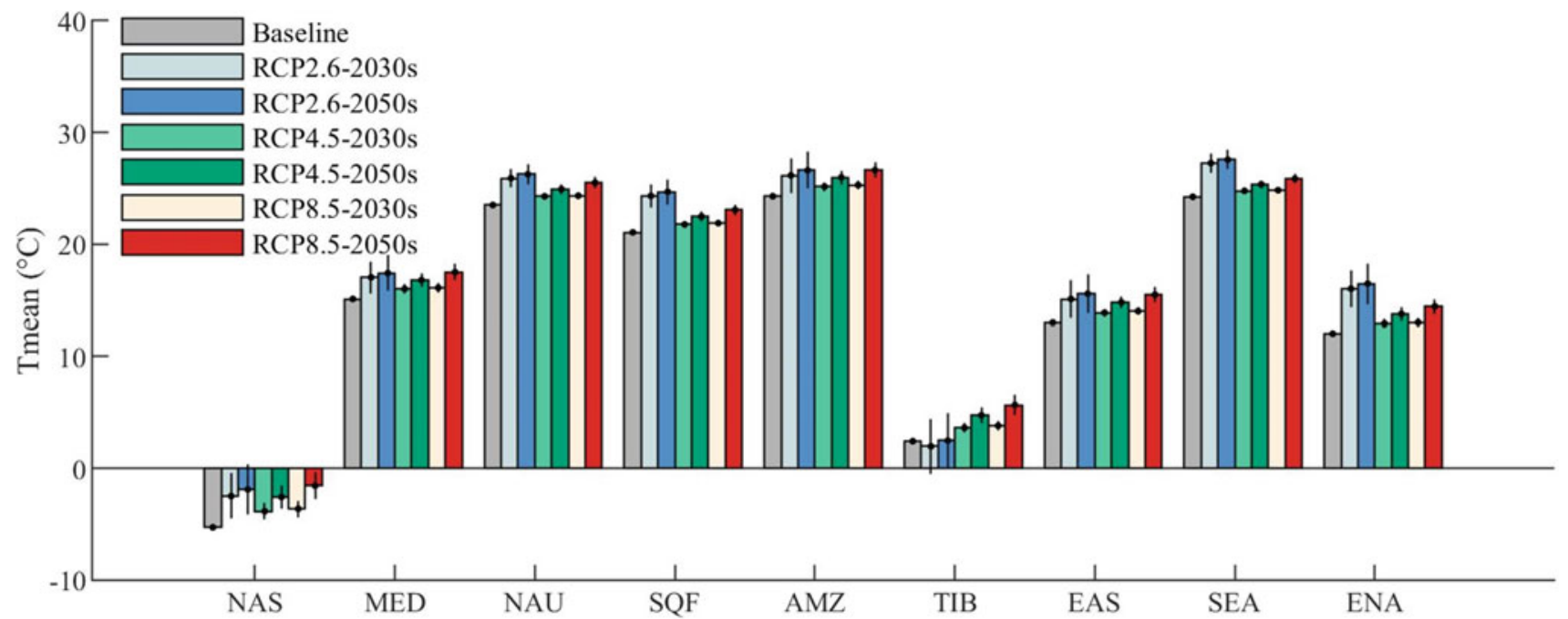

Fig. 1 Area-averaged Tmean in nine regions under different Representative Concentration Pathway (RCP) scenarios. The error bar represents the one standard deviation across all selected models-13 general circulation models (GCMs) (RCP2.6) and 21 GCMs (RCP4.5 and RCP8.5). NAS, MED, NAU, SQF, AMZ, TIB, EAS, SEA, and ENA represent North Asia $\left(47-70^{\circ} \mathrm{N}, 60.5-180.5^{\circ} \mathrm{E}\right)$, Mediterranean
Basin $\left(30-47^{\circ} \mathrm{N}, 10.5^{\circ} \mathrm{W}-37.5^{\circ} \mathrm{E}\right)$, Northern Australia $\left(28-10^{\circ} \mathrm{S}\right.$, $\left.109.5-155.5^{\circ} \mathrm{E}\right)$, South Equatorial Africa $\left(26-0^{\circ} \mathrm{S}, 0.5-55.5^{\circ} \mathrm{E}\right)$, Amazon Basin $\left(20^{\circ} \mathrm{S}-10^{\circ} \mathrm{N}, 78.5-34.5^{\circ} \mathrm{W}\right)$, Tibet $\left(30-47^{\circ} \mathrm{N}, 80.5-104.5^{\circ}\right.$ E), East Asia $\left(20-47^{\circ} \mathrm{N}, 104.5-140.5^{\circ} \mathrm{E}\right)$, Southeast Asia $\left(10^{\circ} \mathrm{S}-20^{\circ} \mathrm{N}\right.$, $\left.100.5-150.5^{\circ} \mathrm{E}\right)$, and Eastern North America $\left(25-50^{\circ} \mathrm{N}, 85.5-60.5^{\circ} \mathrm{W}\right)$, respectively. The regional division follows Giorgi and Bi (2005) 


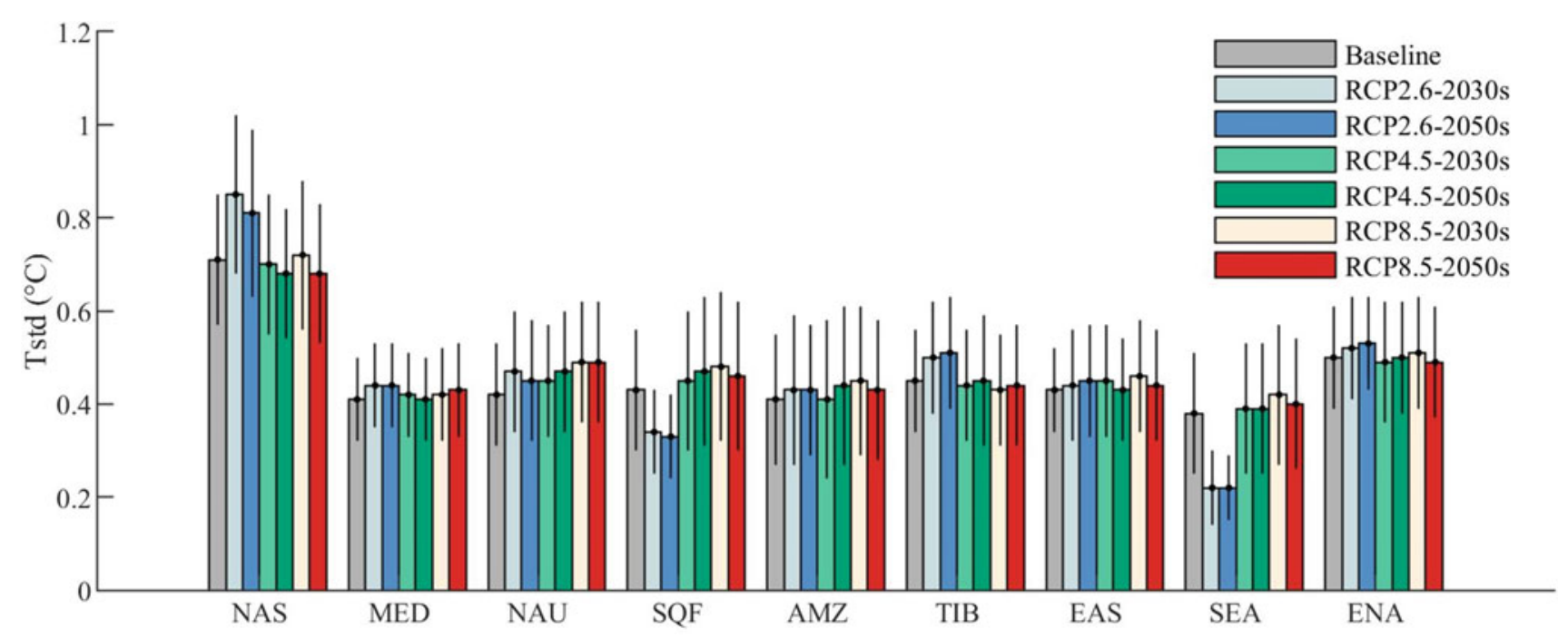

Fig. 2 Standard deviation of the daily mean temperature $(T s t d)$ in nine regions under different Representative Concentration Pathway (RCP) scenarios. The error bar represents the one standard deviation across all selected models. Region abbreviations are the same as in Fig. 1

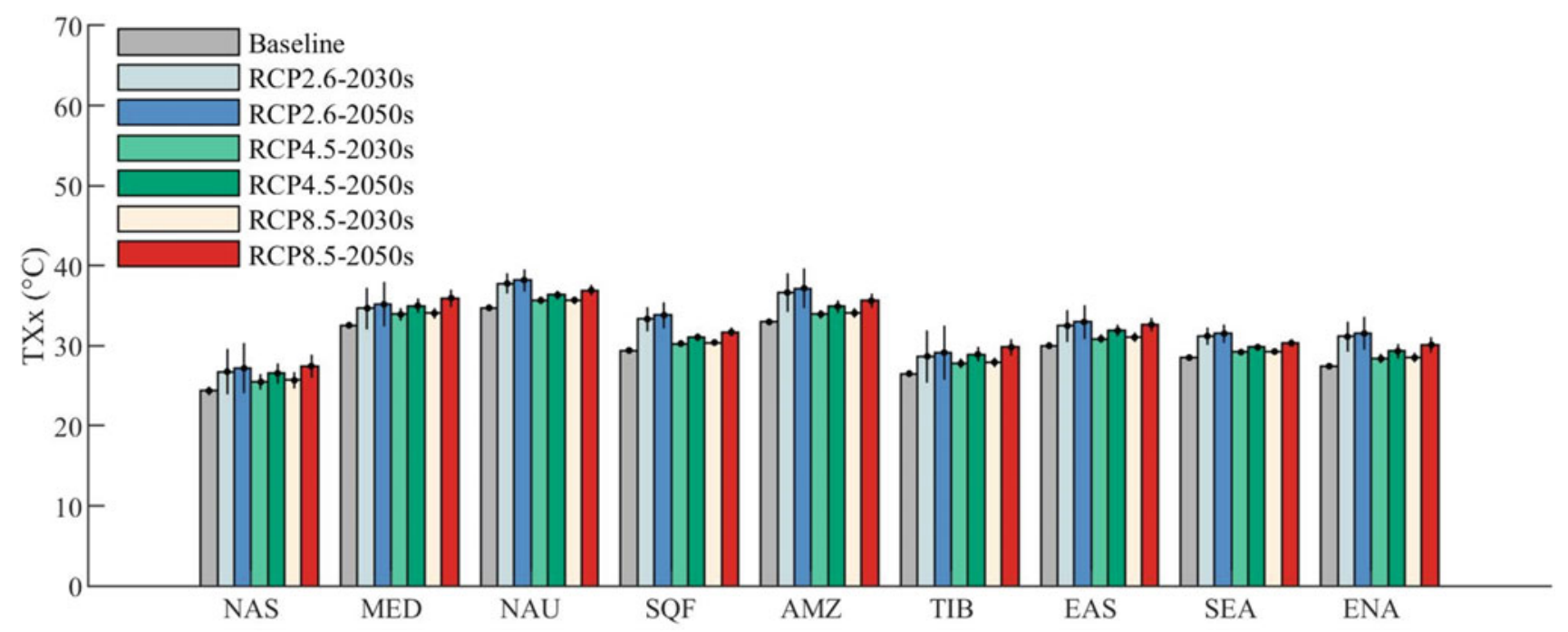

Fig. 3 Annual maximum near-surface air temperature $(\boldsymbol{T X} \boldsymbol{X})$ in nine regions under different Representative Concentration Pathway (RCP) scenarios. The error bar represents the one standard deviation across all selected models. Region abbreviations are the same as in Fig. 1

The standard deviations of the daily mean temperature for the nine regions under different greenhouse gas emissions scenarios are shown in Fig. 2. The temperature deviations in most areas are about $0.4{ }^{\circ} \mathrm{C}$ in all scenarios. In comparison, the North Asia region exhibits the largest temperature deviation with high uncertainty, while the lowest deviations appear in South Equatorial Africa and Southeast Asia under the RCP2.6 scenarios.

The annual maximum near-surface air temperature for the nine regions under different RCP scenarios is shown for three epochs in Fig. 3. Similar to the Tmean, the rising $T X x$ occurs in all regions under all scenarios in comparison with the historical period (gray bar). Regions with high $T X x$ are mainly located in the Mediterranean Basin, Northern Australia, and the Amazon Basin. Additionally, the TXx difference between the 2050s and the 2030s is larger under the RCP8.5 scenarios.

The percentage of the days with a daily maximum temperature greater than the 90th percentile of the base period for the nine regions under different RCP scenarios is shown 


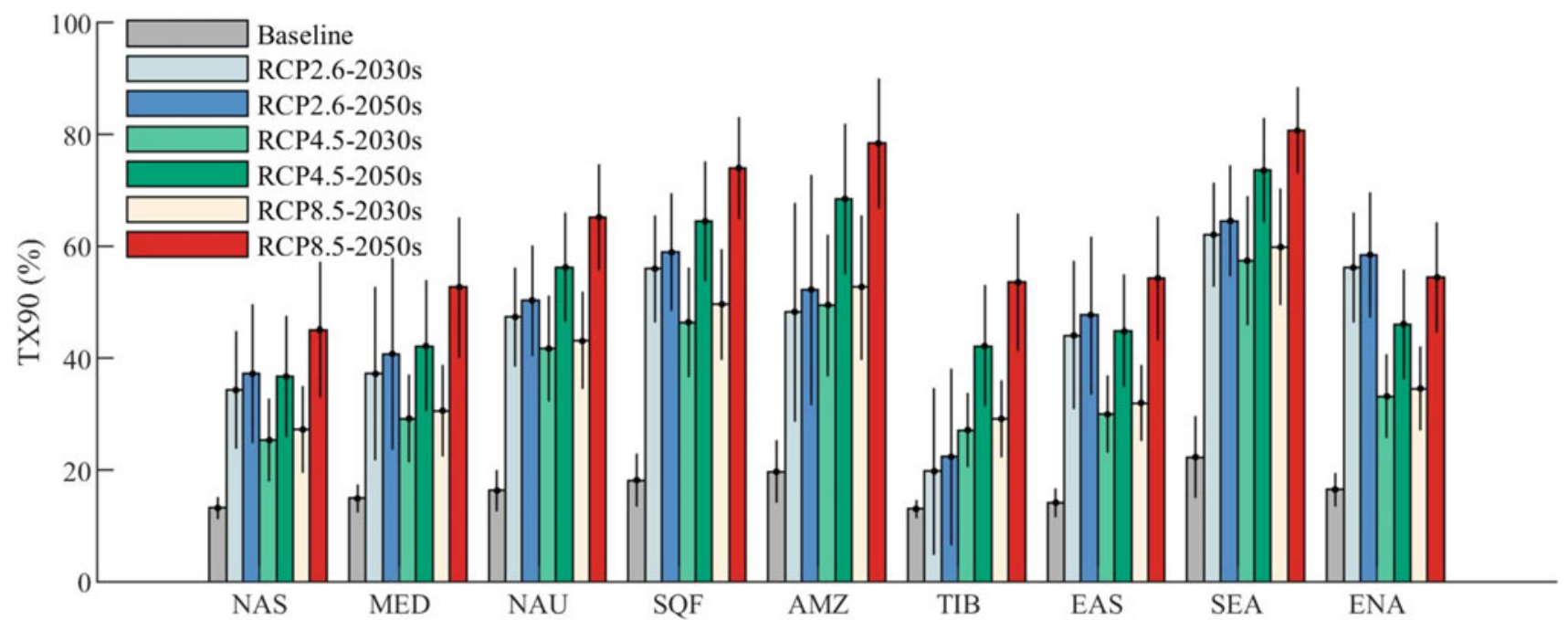

Fig. 4 Percentage of the days with the daily maximum temperature greater than the 90th percentile of the base period (TX90p) in nine regions under different Representative Concentration Pathway

(RCP) scenarios. The error bar represents the one standard deviation across all selected models. Region abbreviations are the same as in Fig. 1

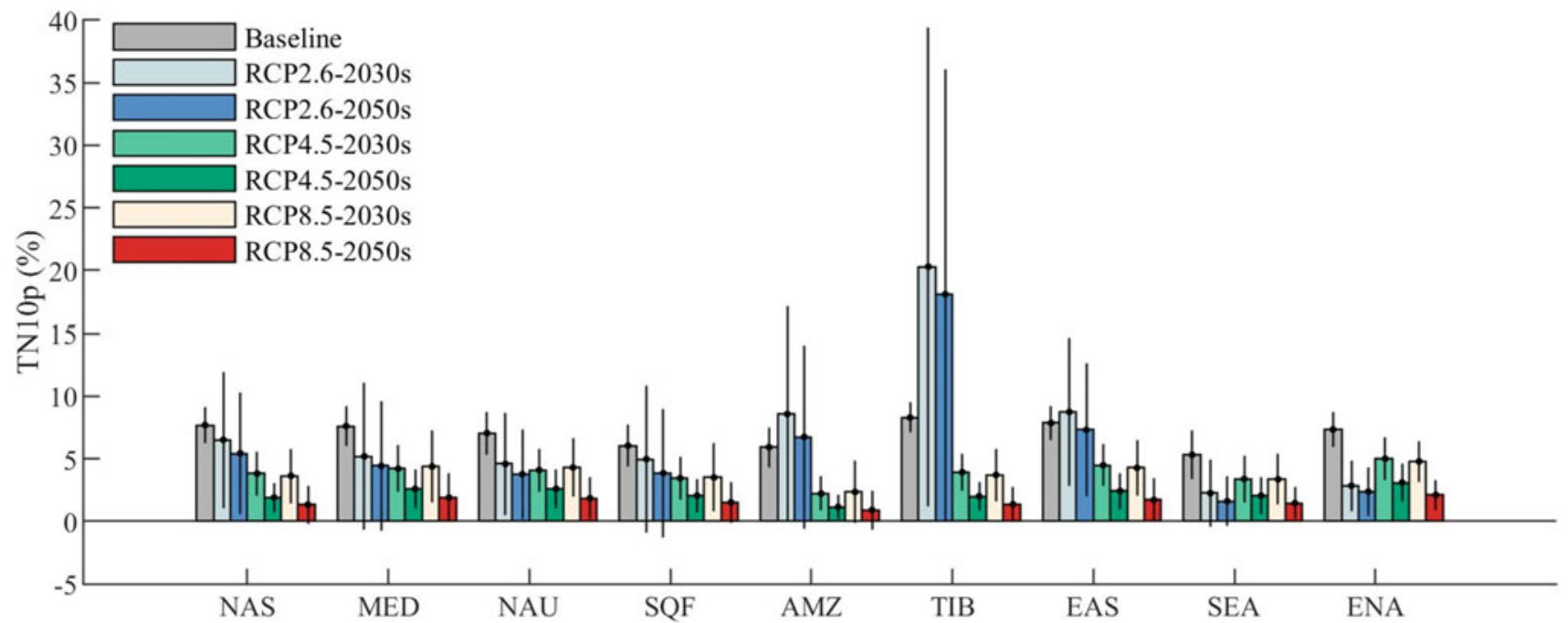

Fig. 5 Percentage of the days with the daily minimum temperature less than the 10th percentile of the base period (TN1Op) in nine regions under three Representative Concentration Pathway (RCP) scenarios.
The error bar represents the one standard deviation across all selected models. Region abbreviations are the same as in Fig. 1 in Fig. 4. Invariably, TX90p will increase significantly in all regions in the future, regardless of the scenario. In particular, in the 2050s, TX90p is expected to even exceed the historical period by a factor of four under the RCP8.5 scenario.

The percentage of the days with the daily minimum temperature less than the 10th percentile of the base period is shown for the nine regions under the three RCP scenarios in three epochs in Fig. 5. Compared to the historical period (gray bar), six of the nine selected regions-North Asia, the Mediterranean Basin, Northern Australia, South Equatorial Africa, Southeast Asia, and Eastern North America-are expected to have a decreased $T N 10 p$ in the future in all RCP scenarios. In the 2030s, TN10p in the other three regions (the Amazon Basin, Tibet, and East Asia) increases under RCP2.6. 


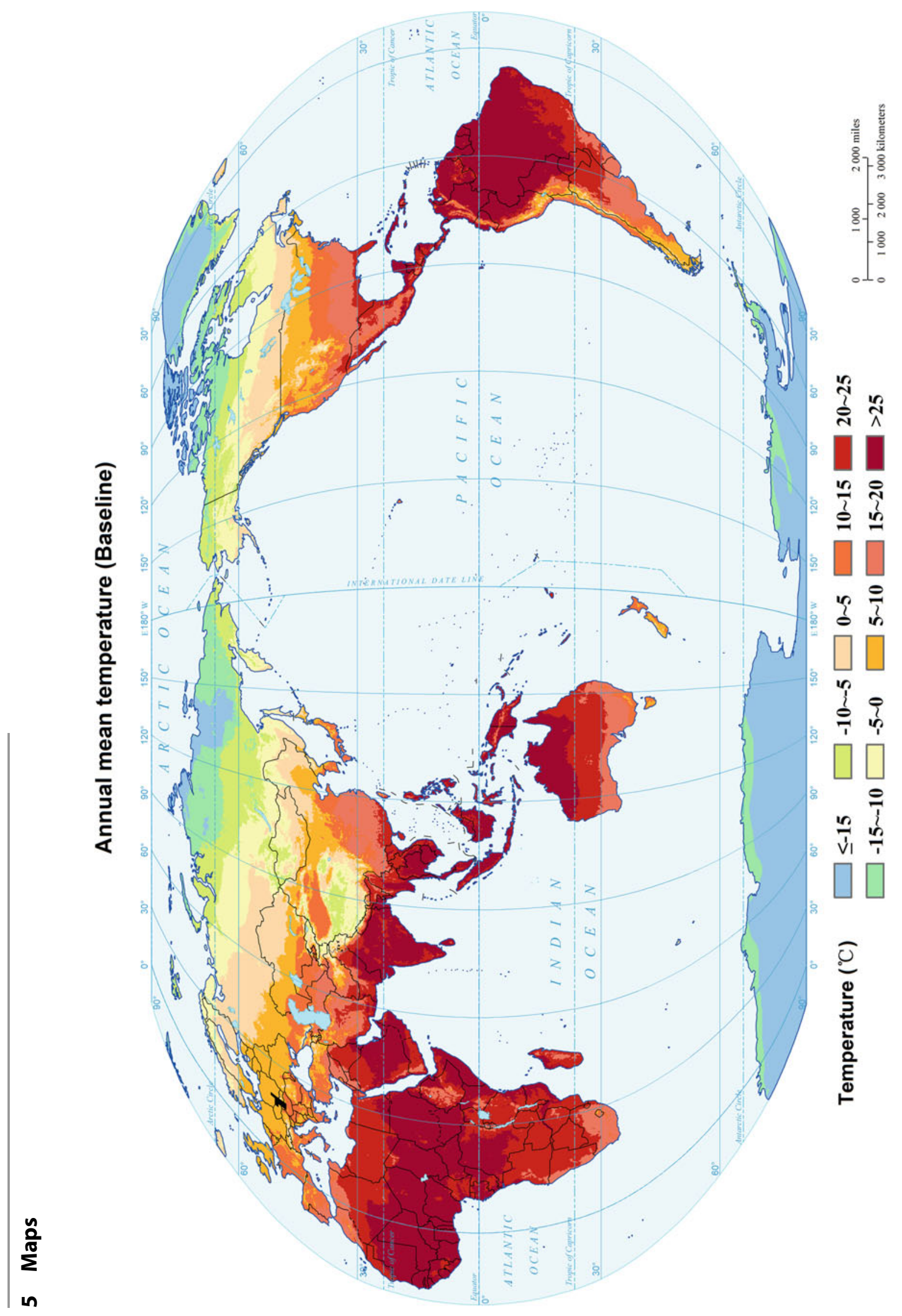


Annual mean temperature (2030s, RCP2.6)

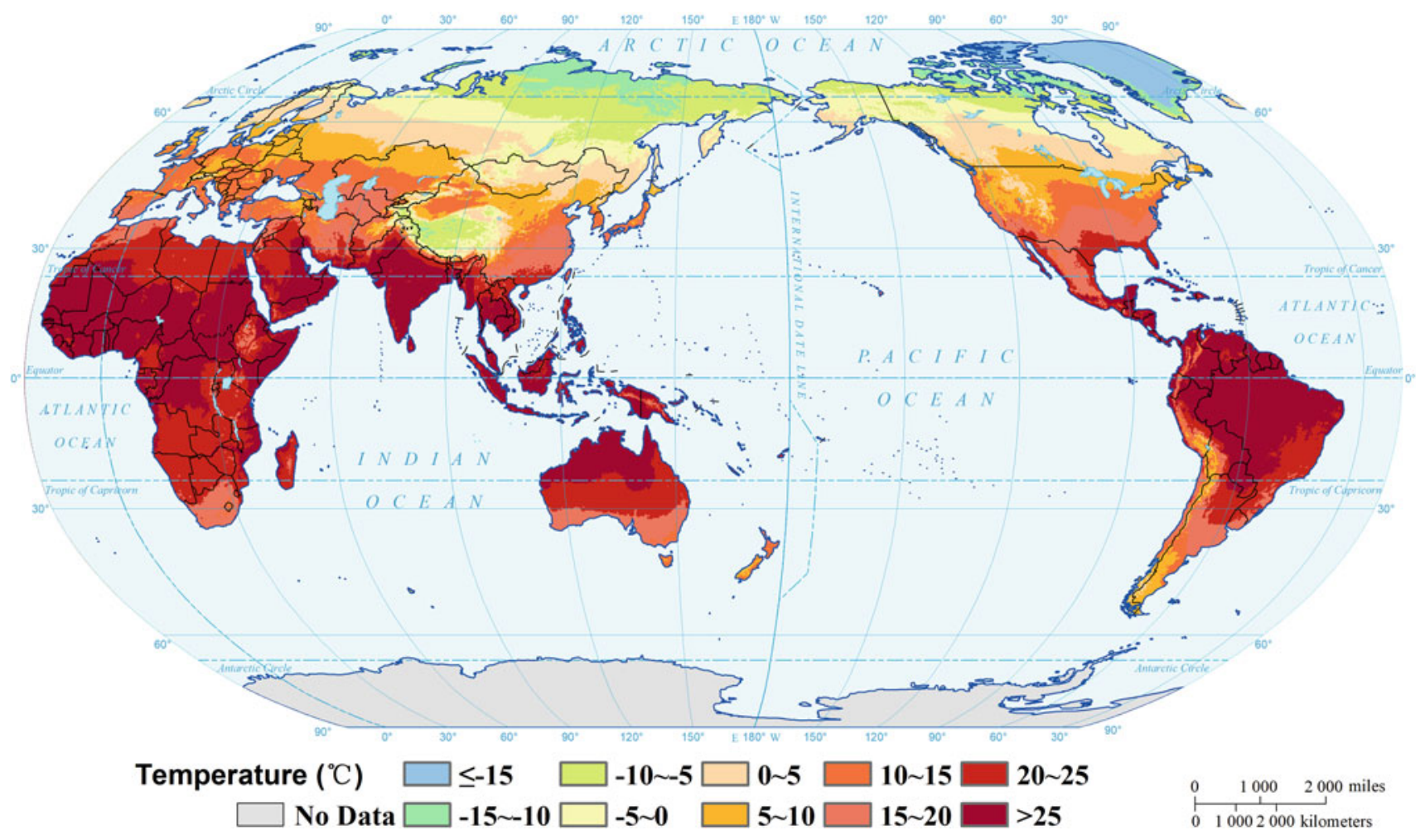

Annual mean temperature (2030s, RCP4.5)

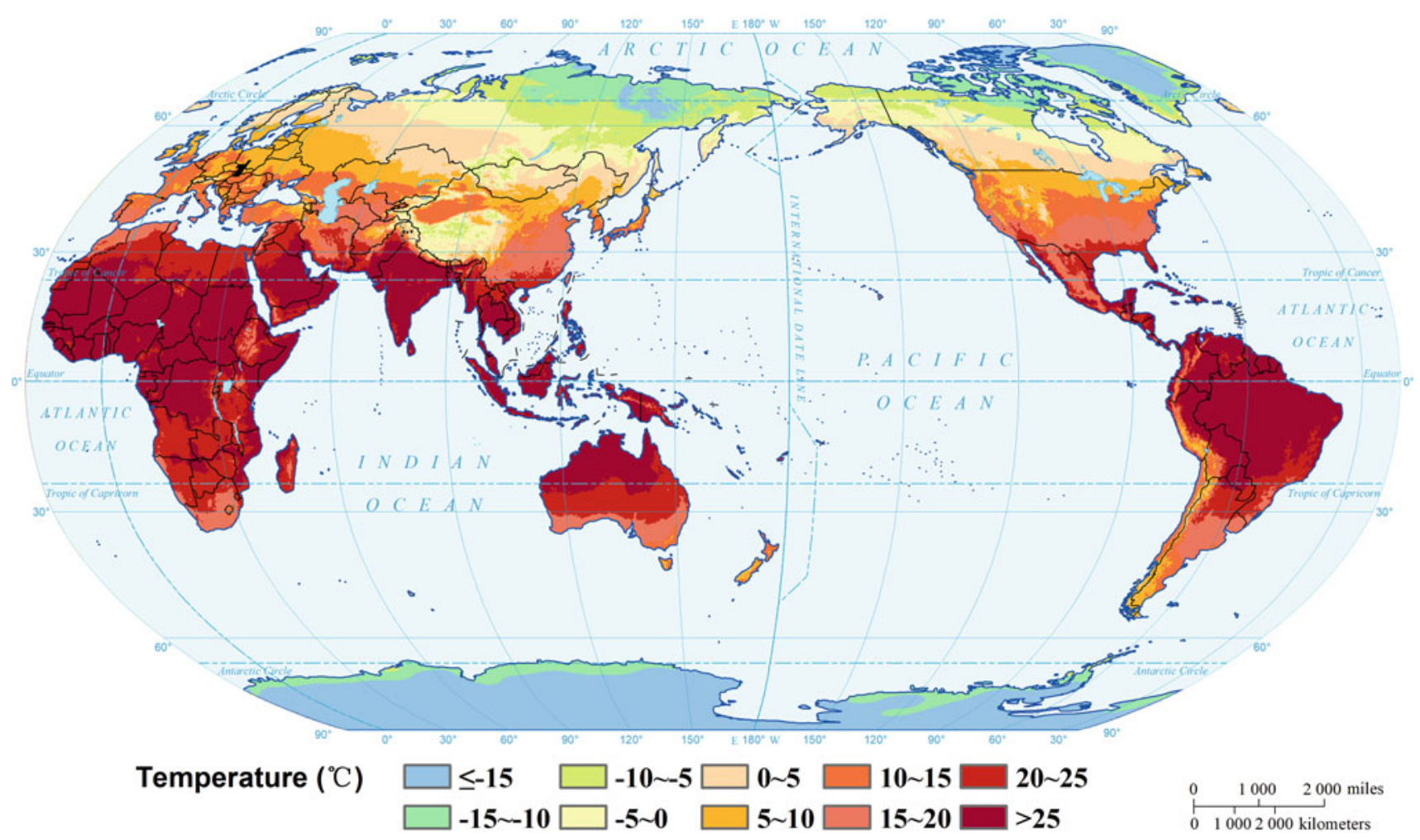


Annual mean temperature (2030s, RCP8.5)

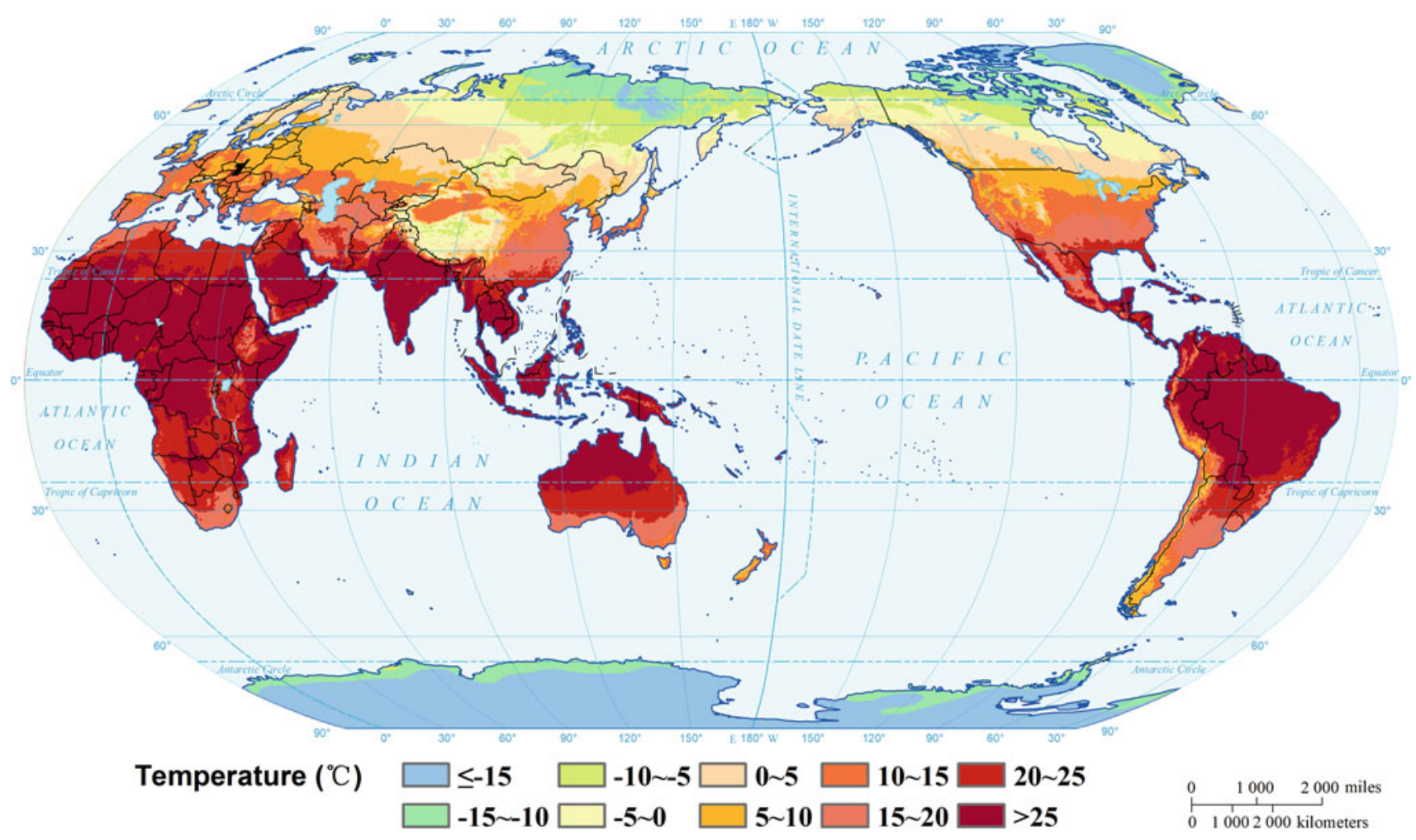

Annual mean temperature (2050s, RCP2.6)

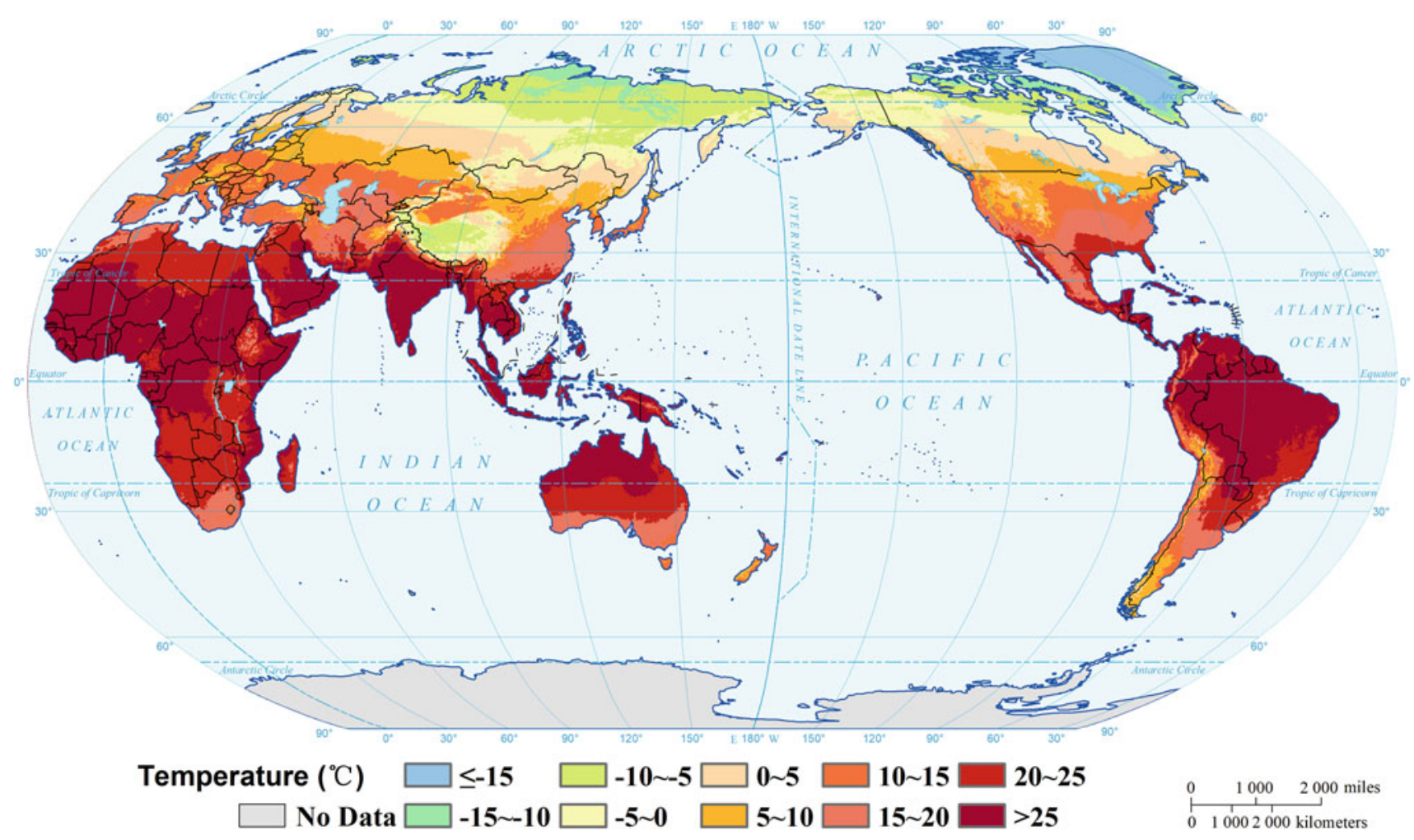


Annual mean temperature (2050s, RCP4.5)

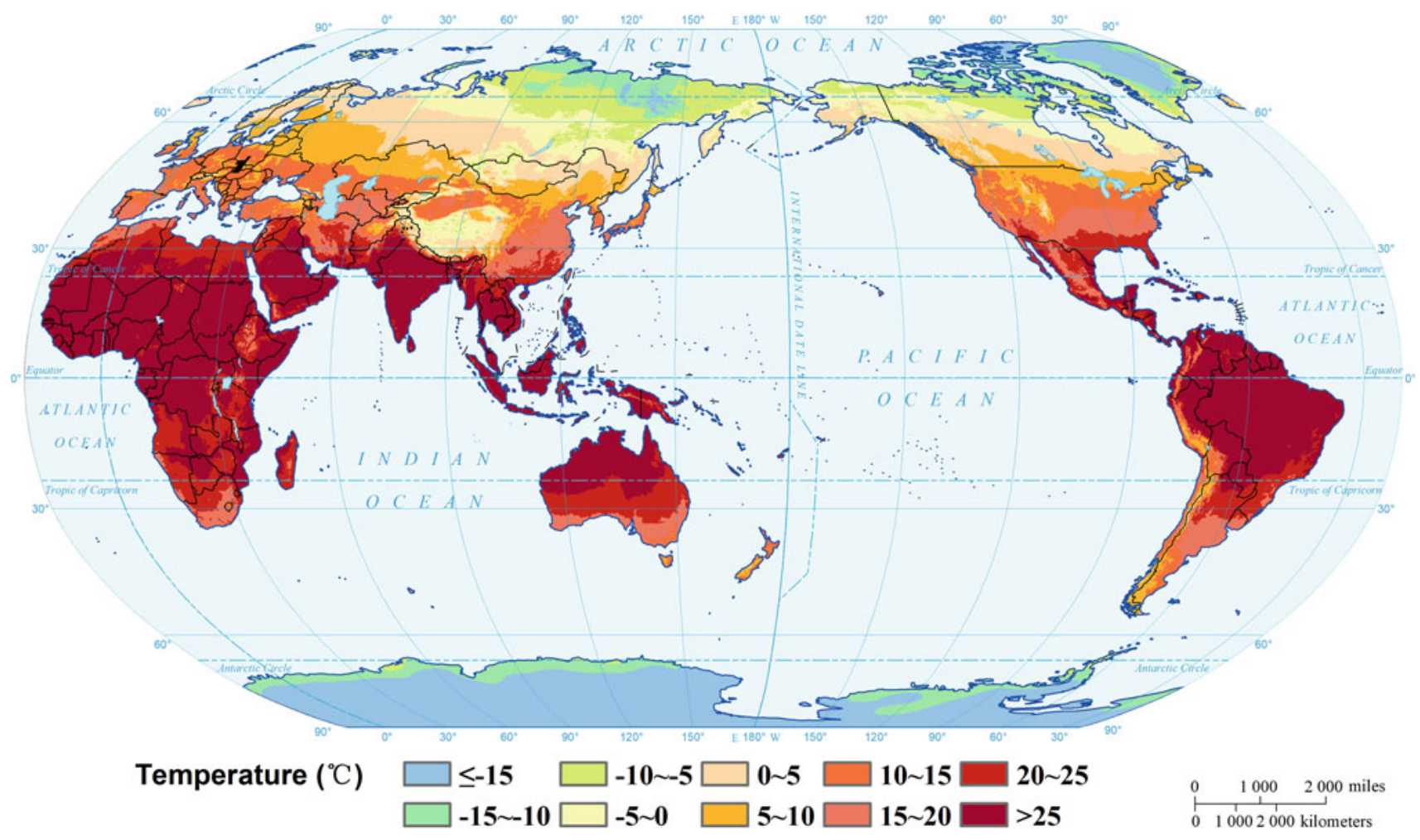

Annual mean temperature (2050s, RCP8.5)

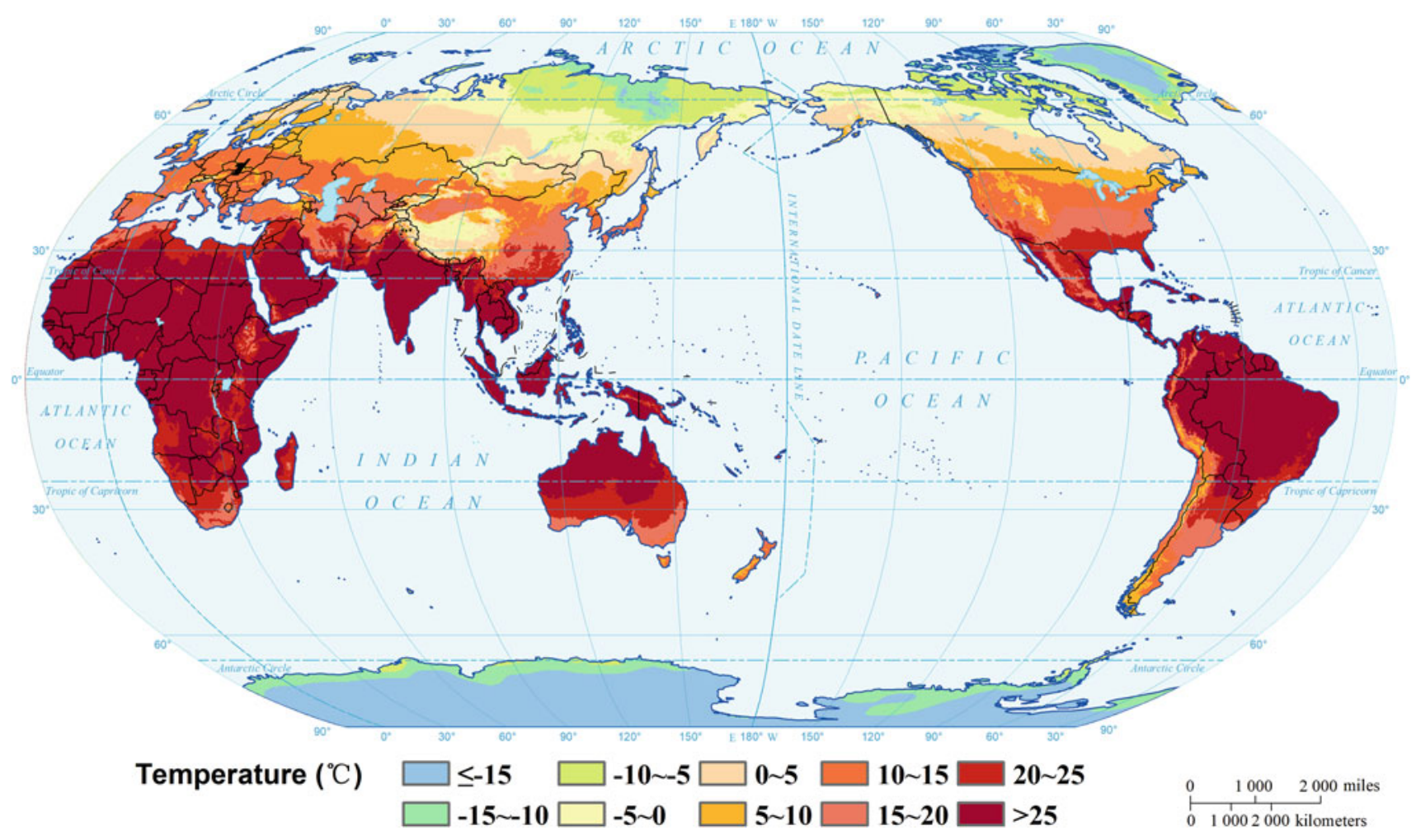




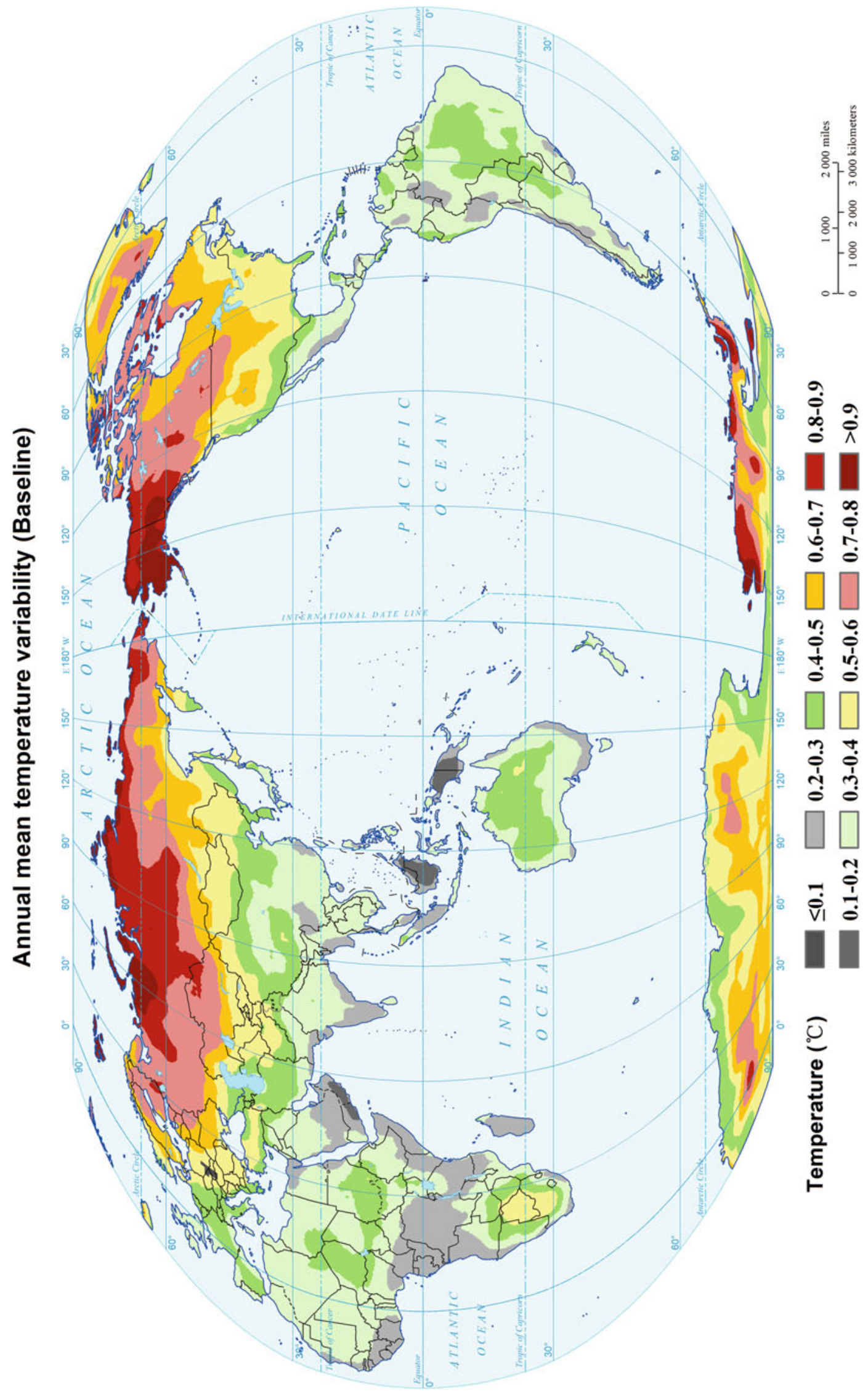


Annual mean temperature variability (2030s, RCP2.6)

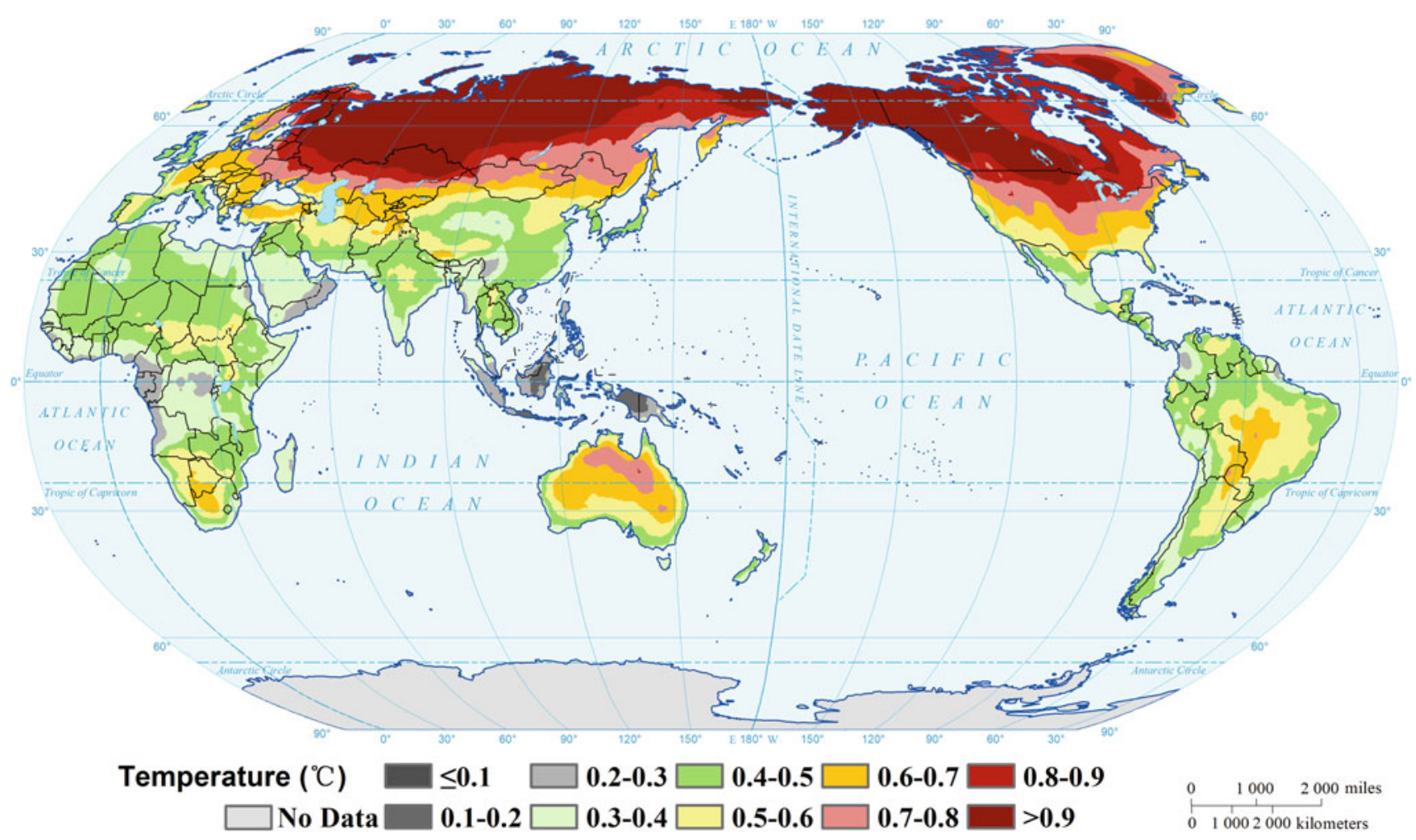

Annual mean temperature variability (2030s, RCP4.5)

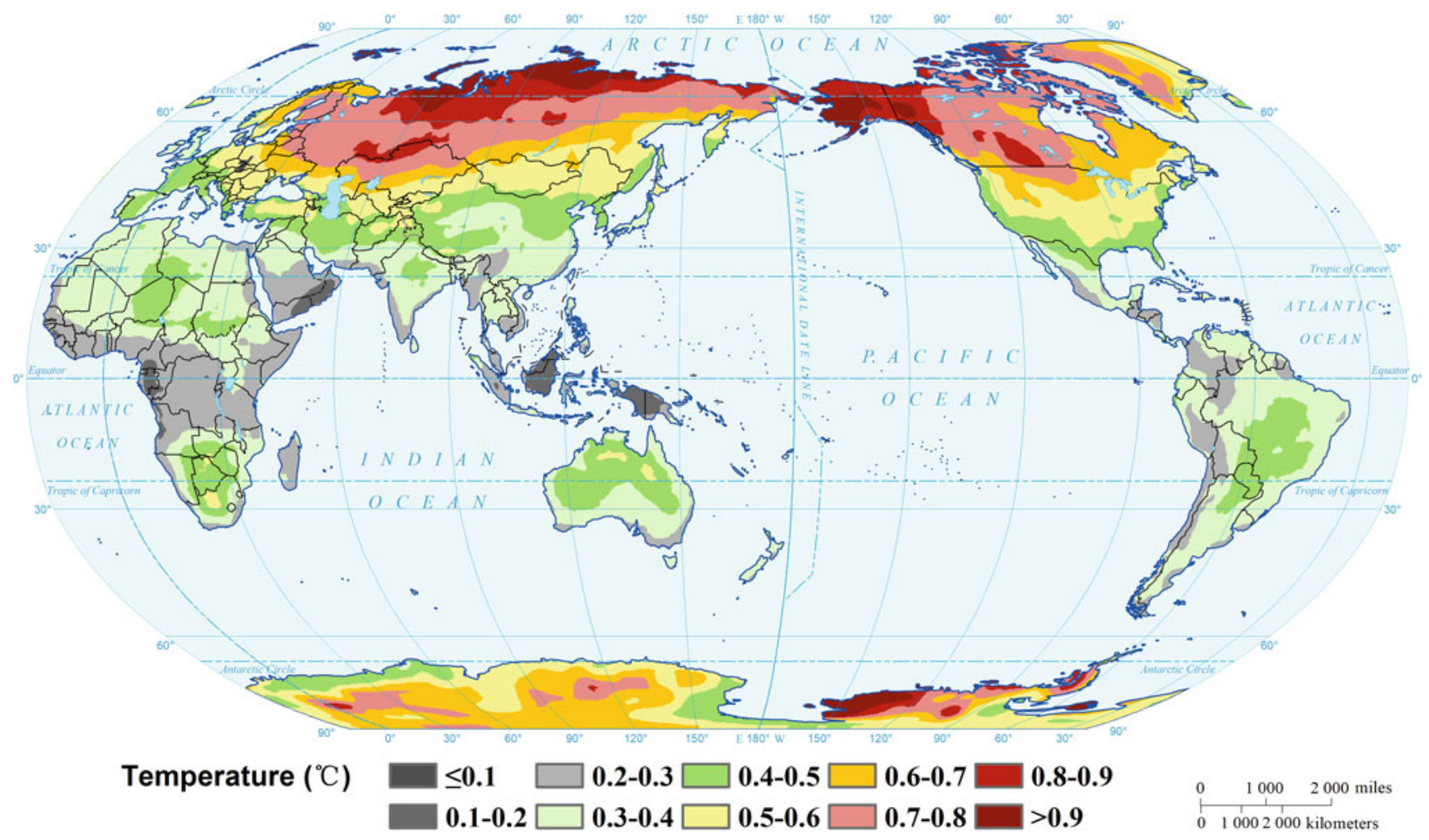


Annual mean temperature variability (2030s, RCP8.5)

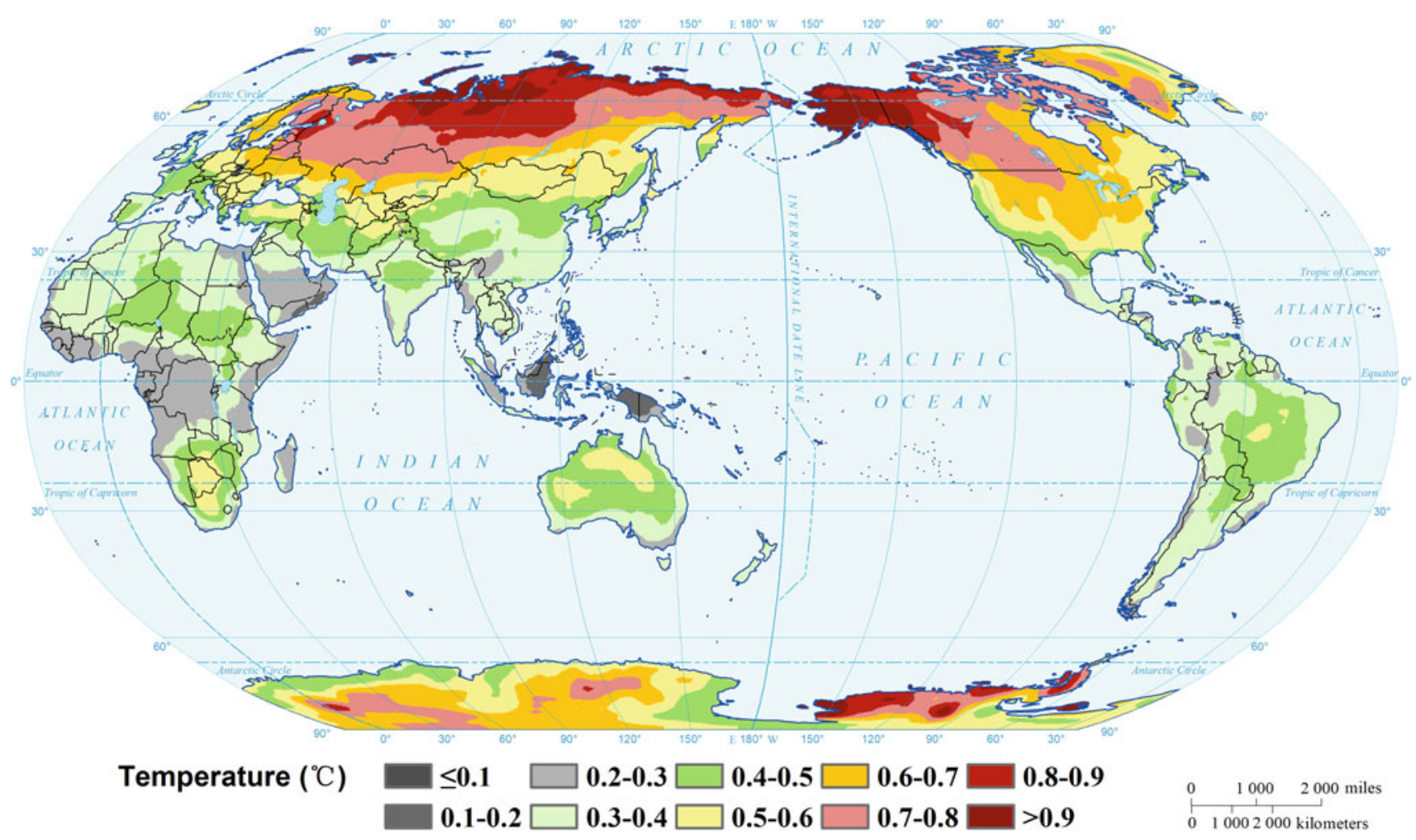

Annual mean temperature variability (2050s, RCP2.6)

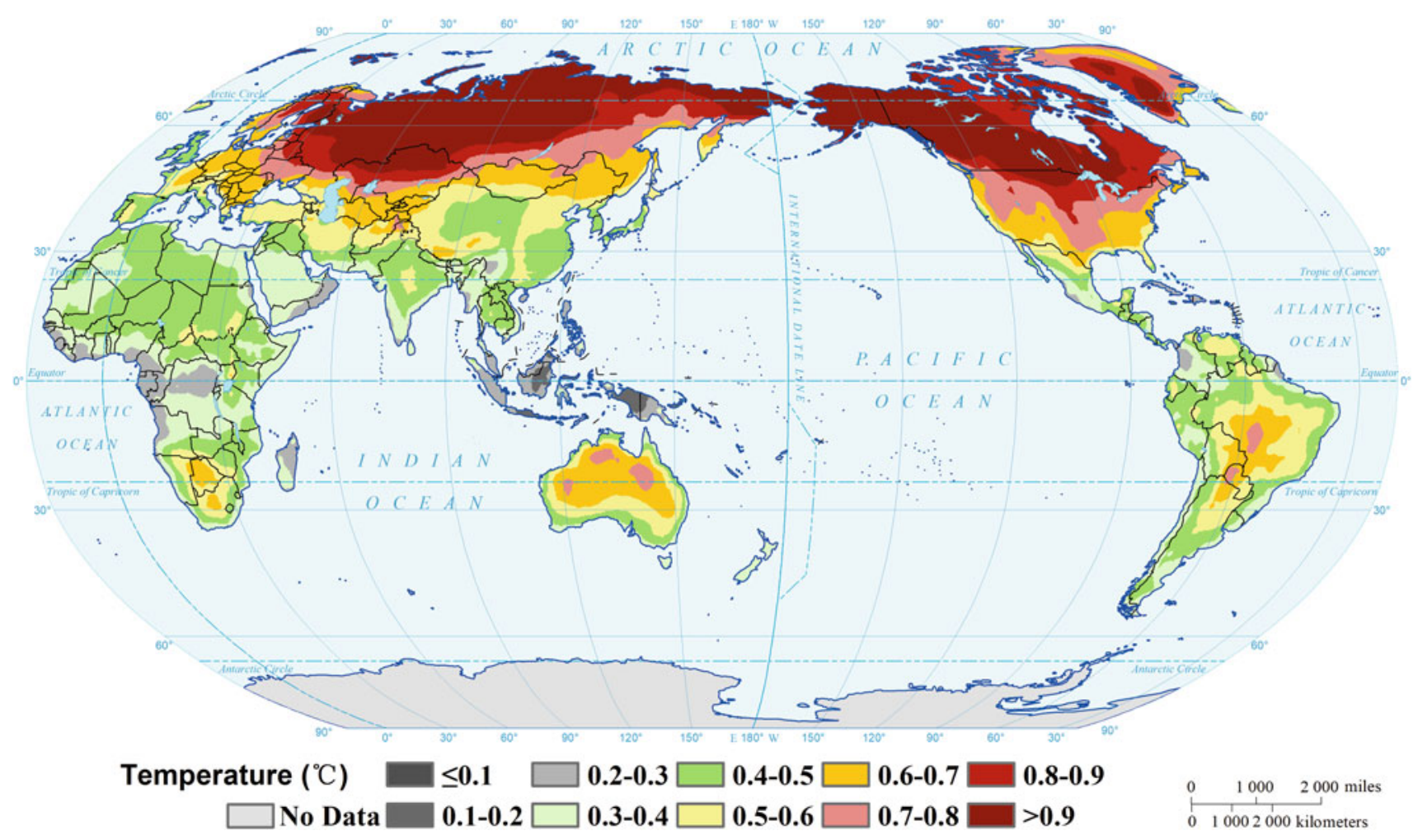


Annual mean temperature variability (2050s, RCP4.5)

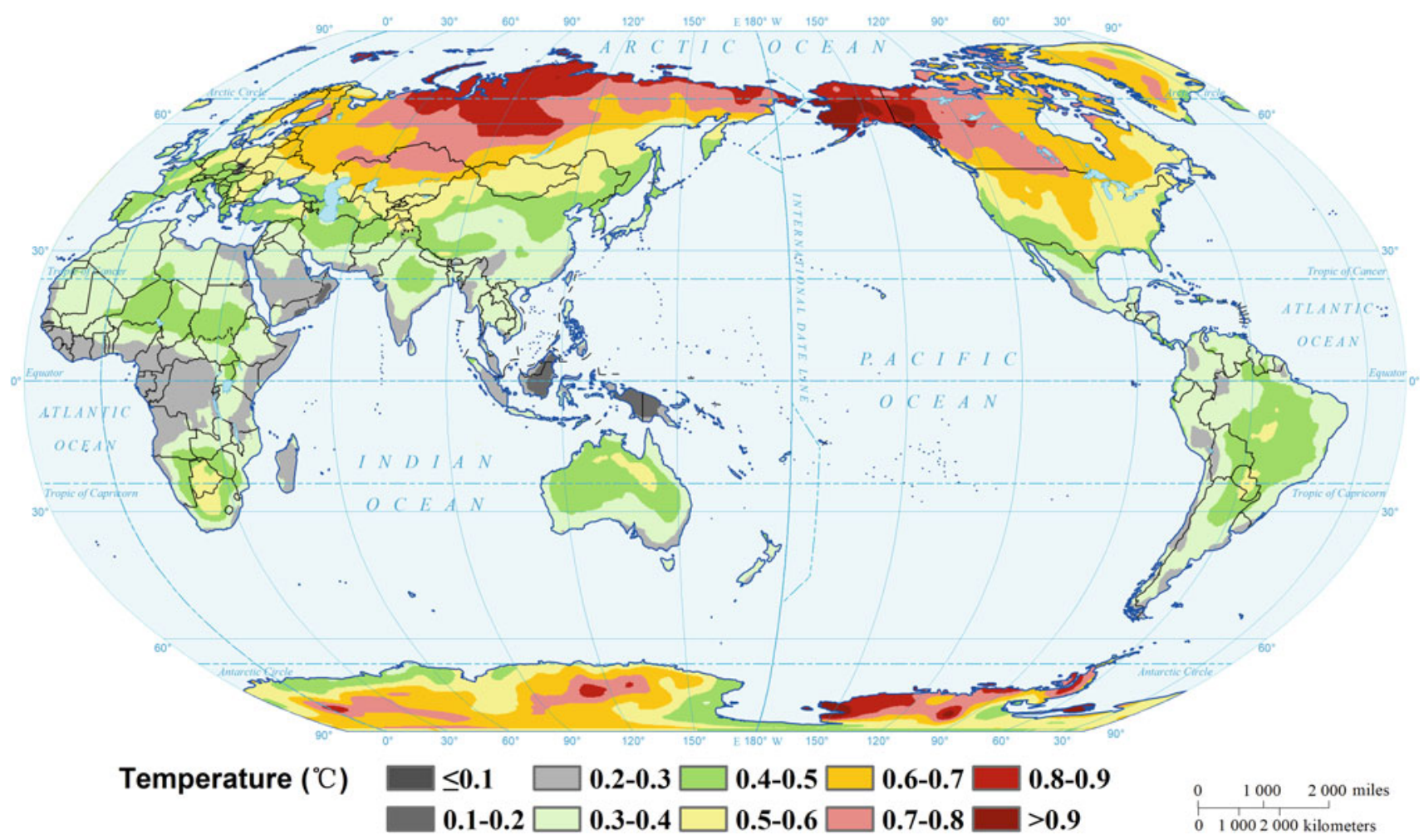

Annual mean temperature variability (2050s, RCP8.5)

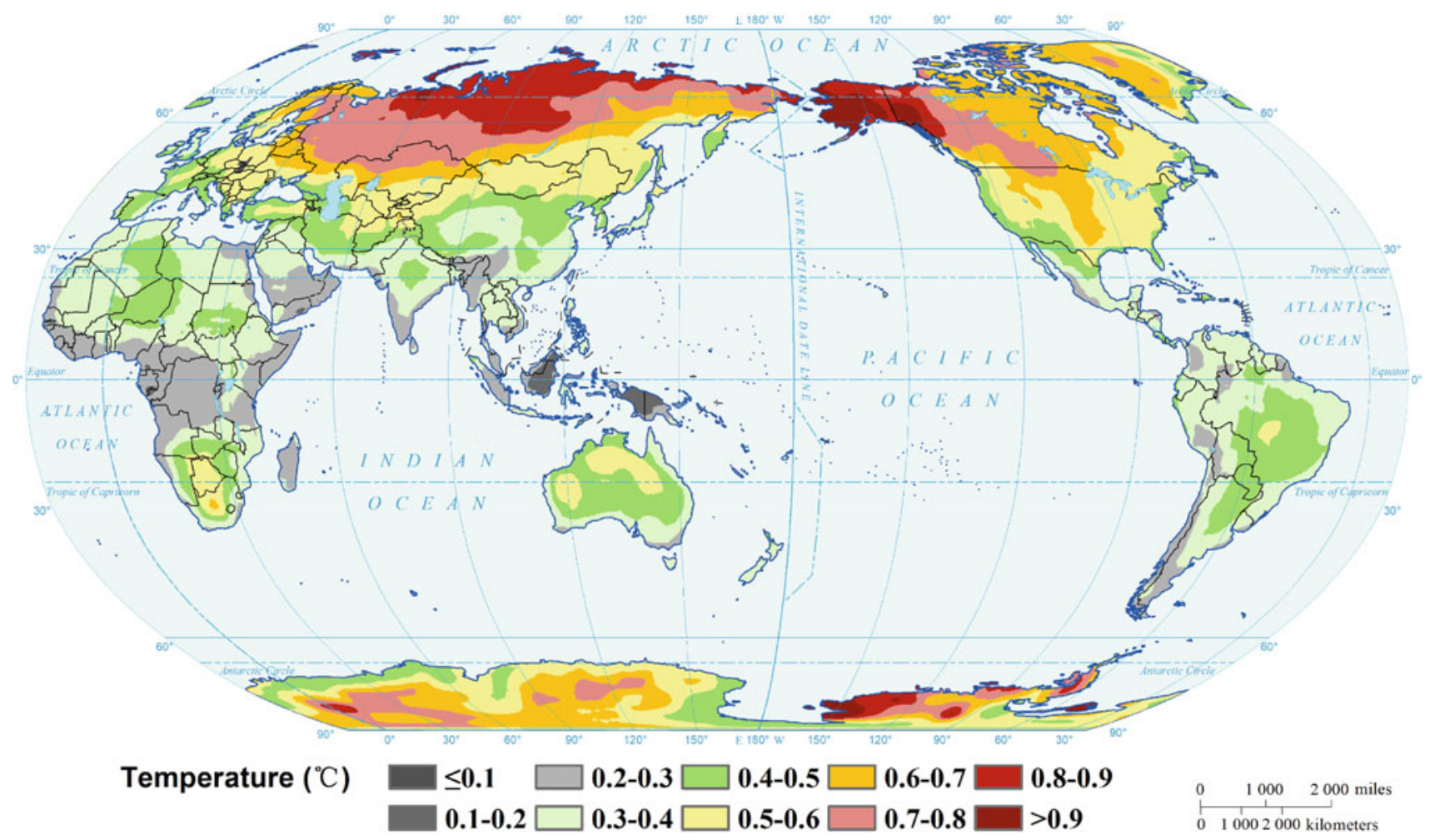




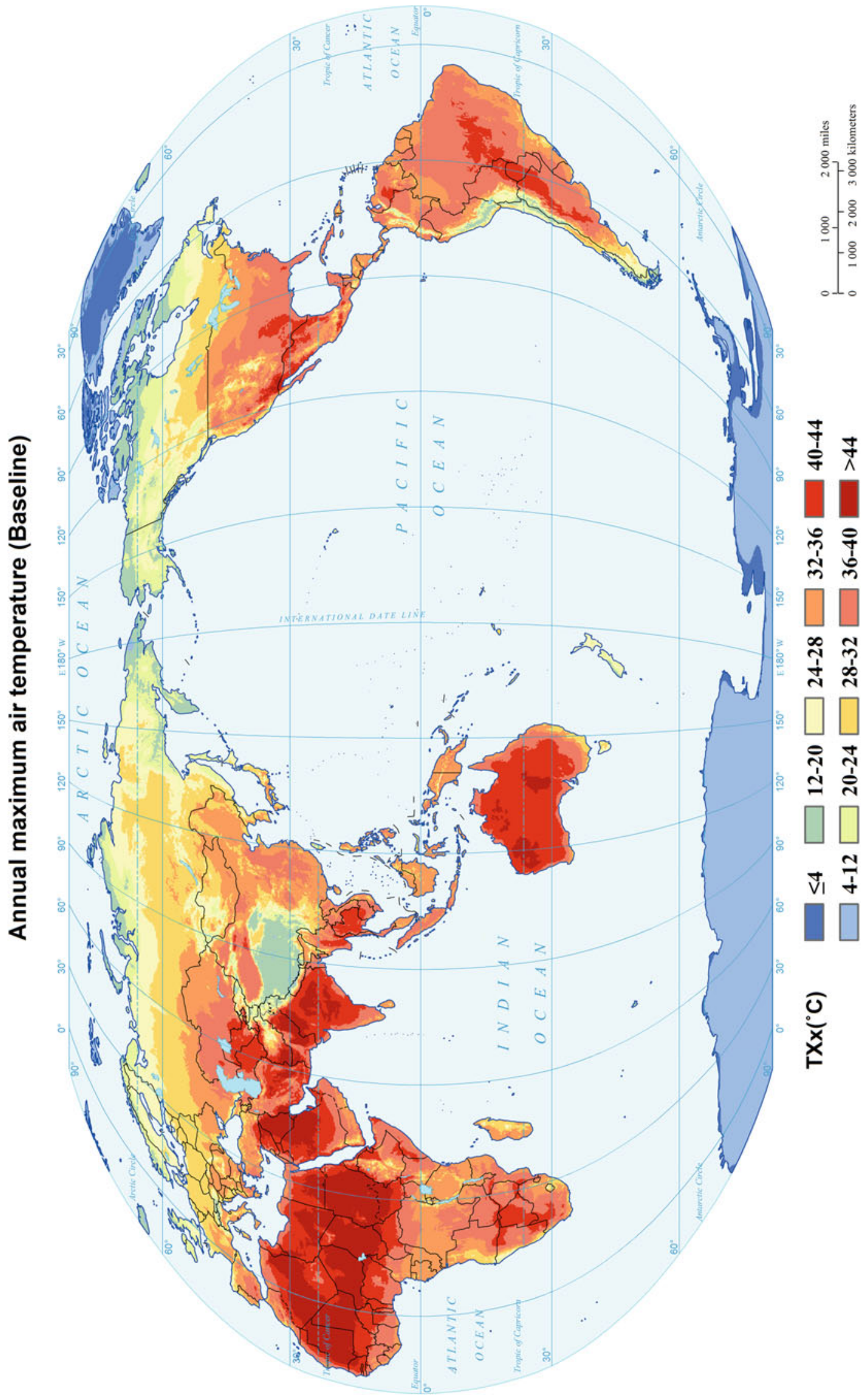


Annual maximum air temperature (2030s, RCP2.6)

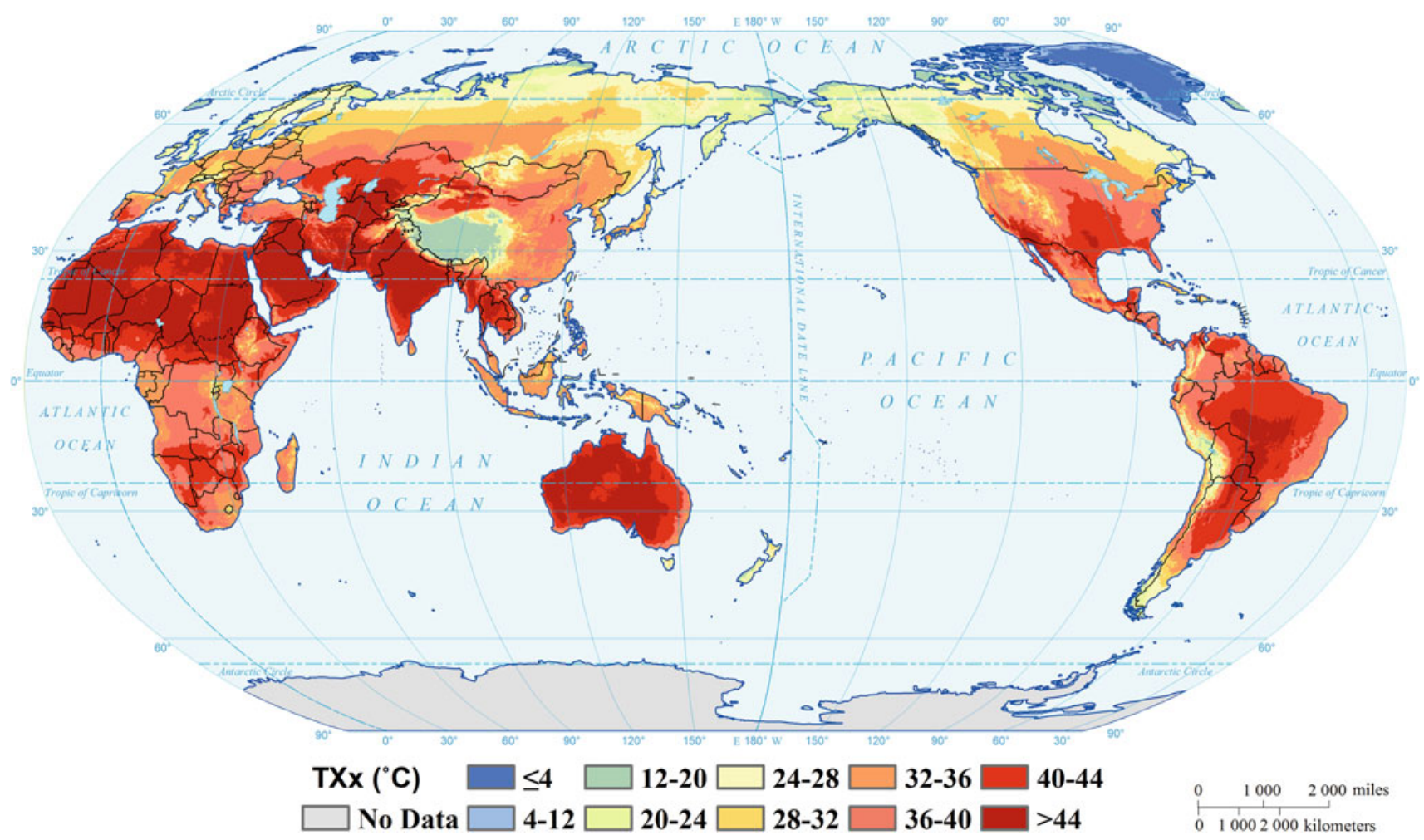

Annual maximum air temperature (2030s, RCP4.5)

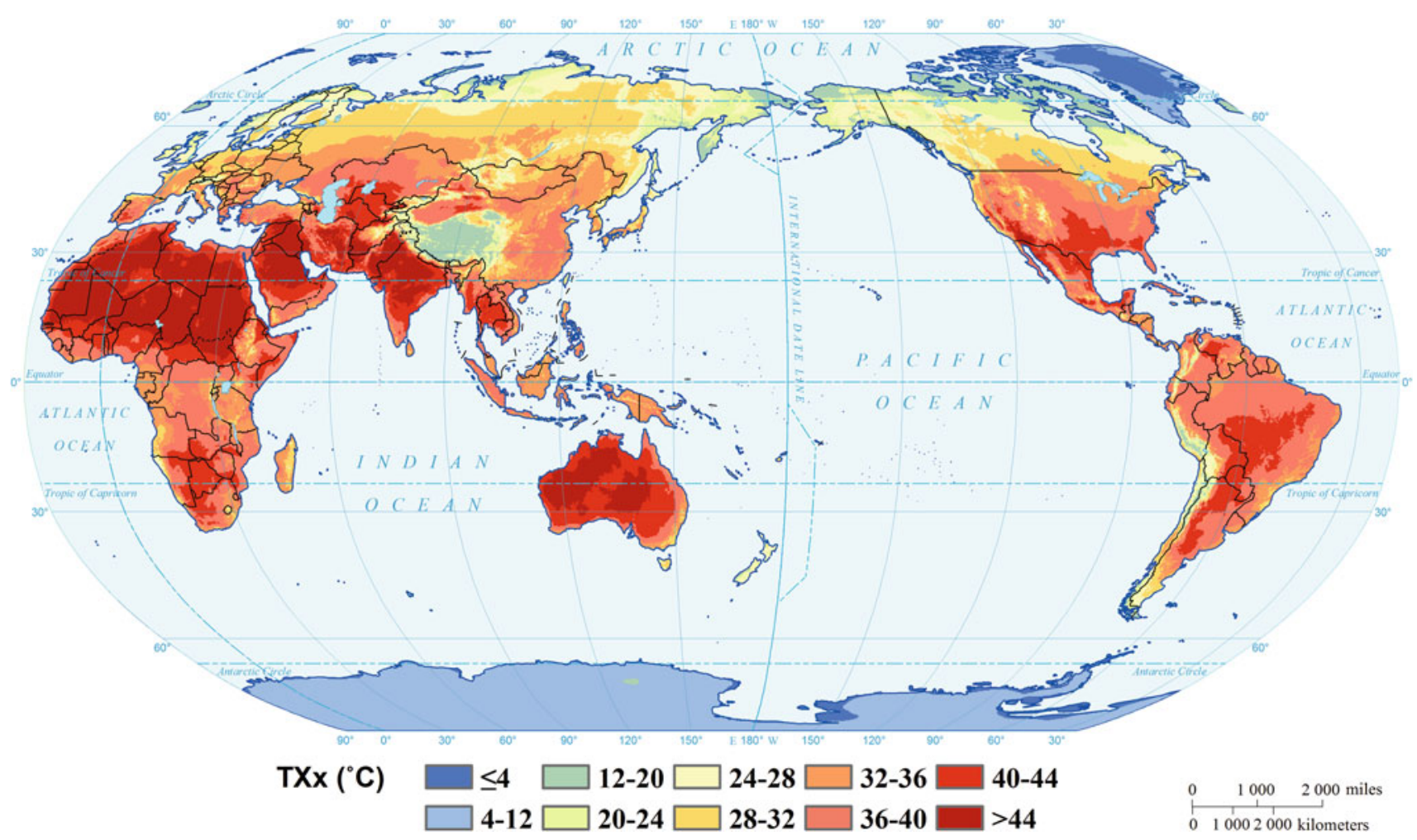


Annual maximum air temperature (2030s, RCP8.5)

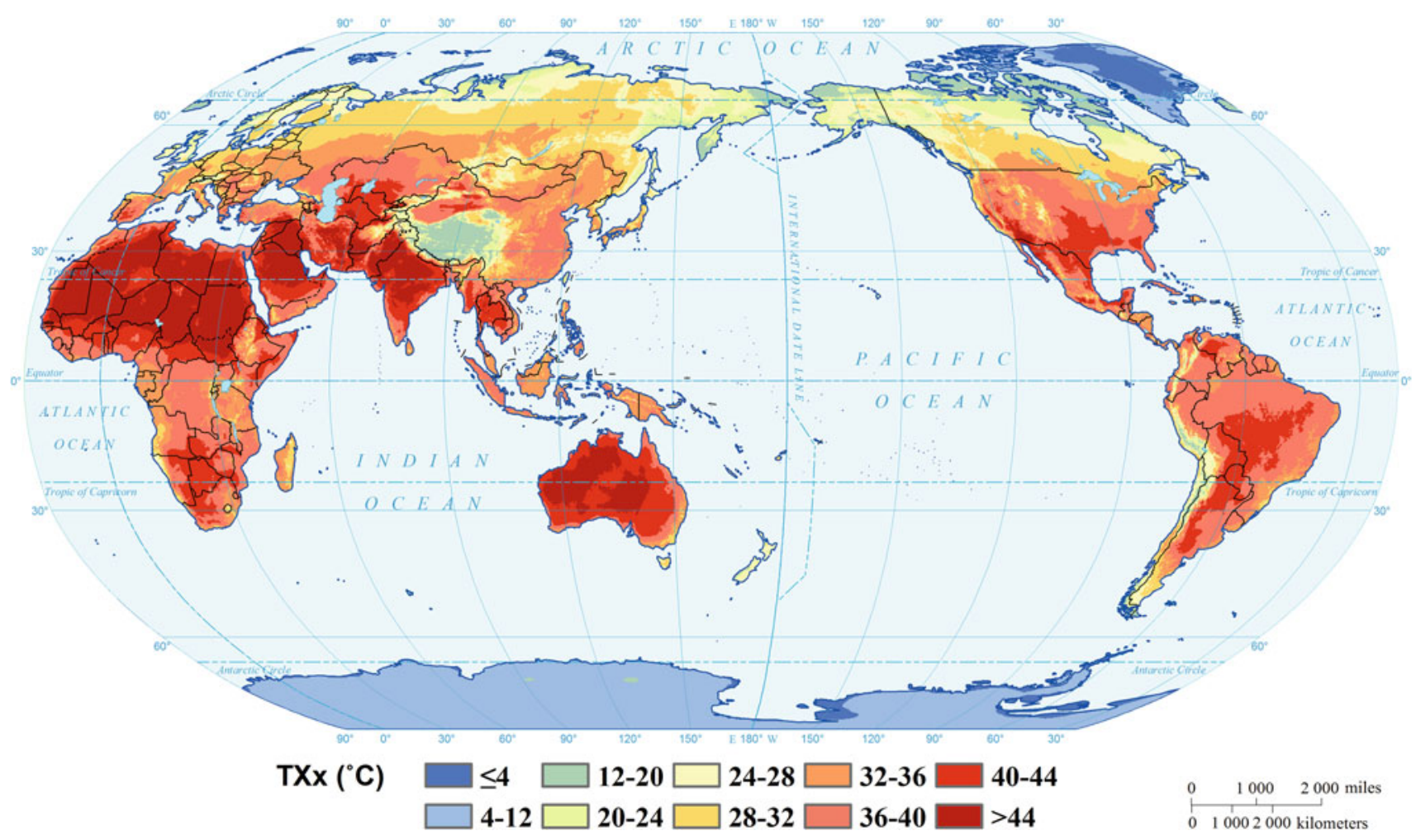

Annual maximum air temperature (2050s, RCP2.6)

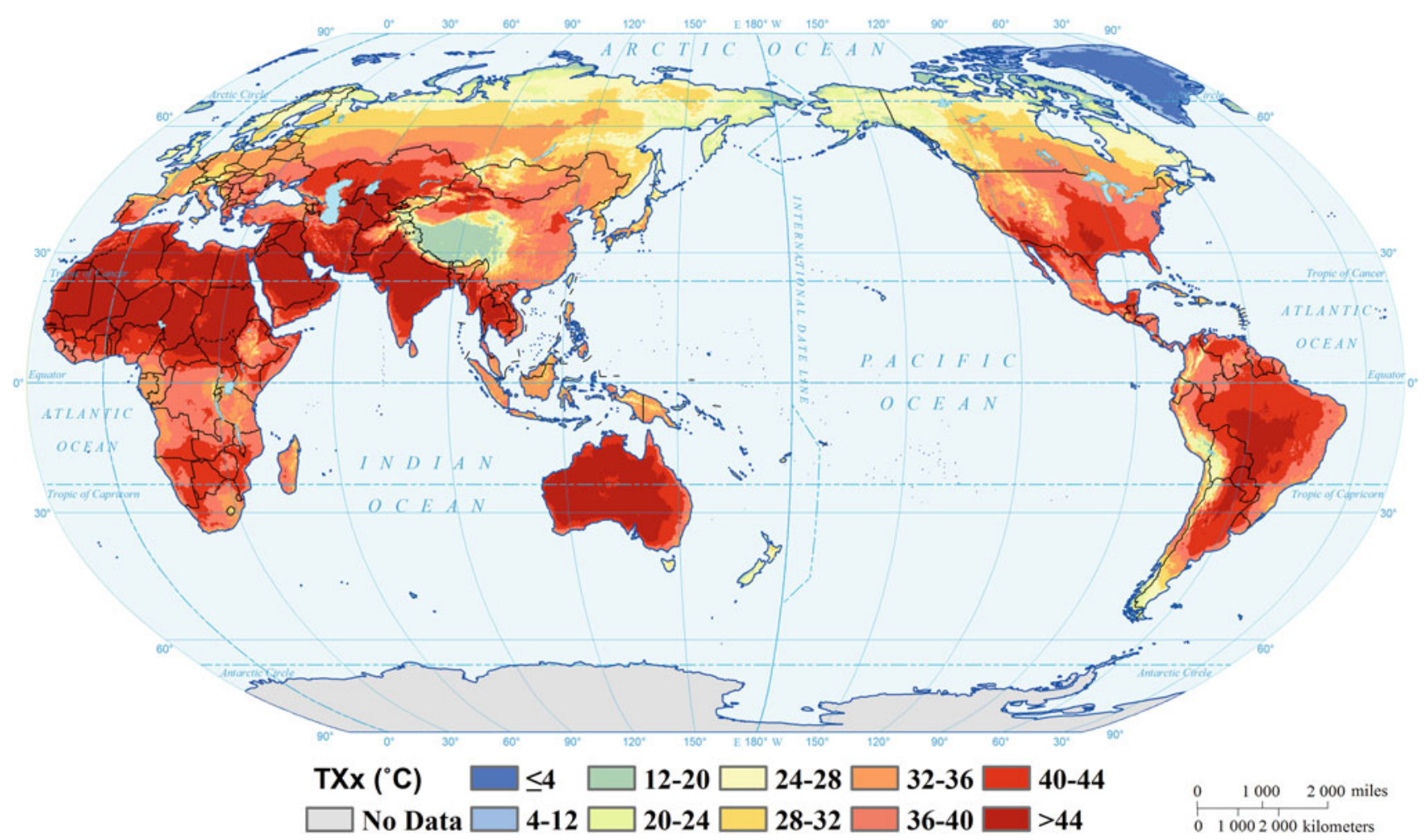


Annual maximum air temperature (2050s, RCP4.5)

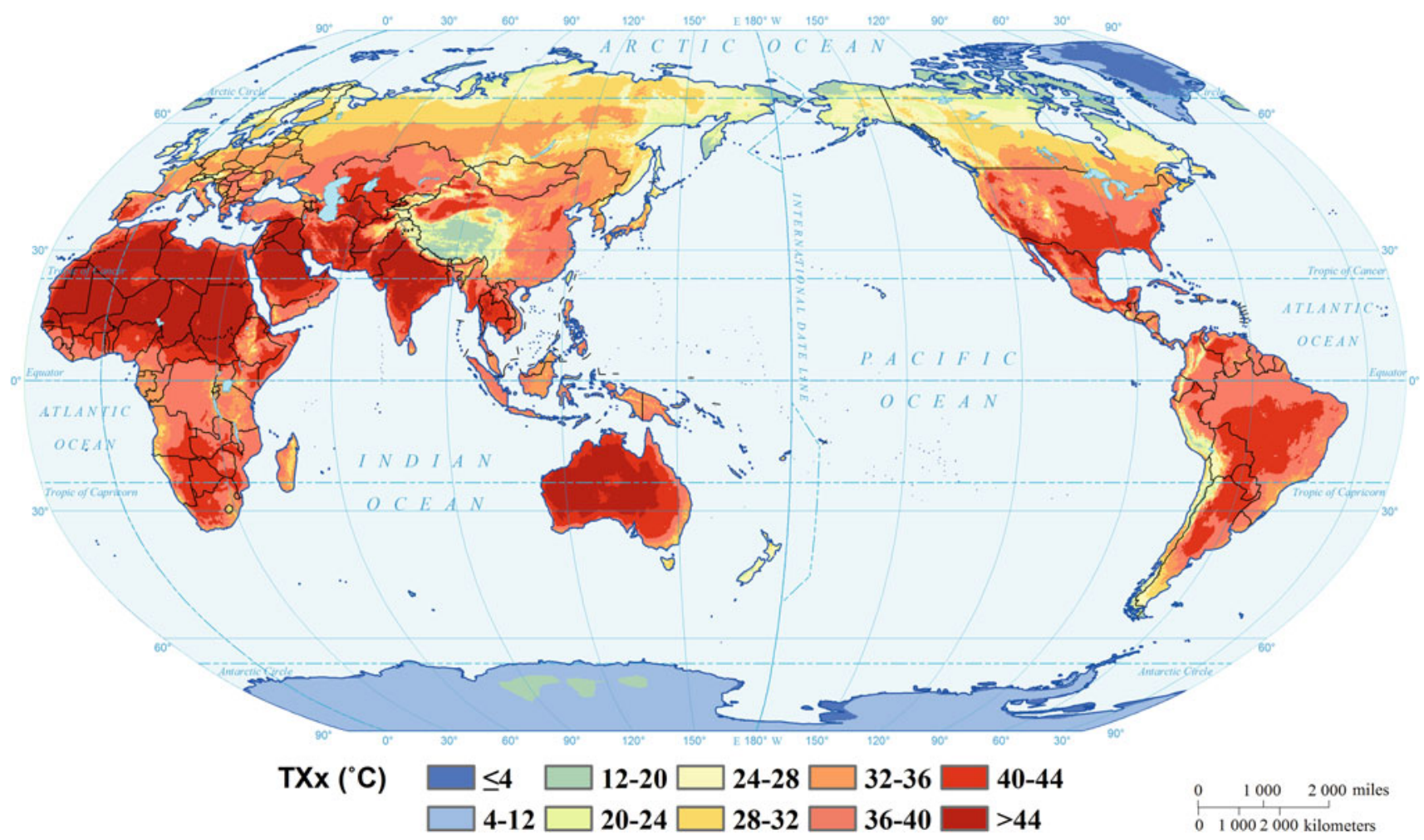

Annual maximum air temperature (2050s, RCP8.5)

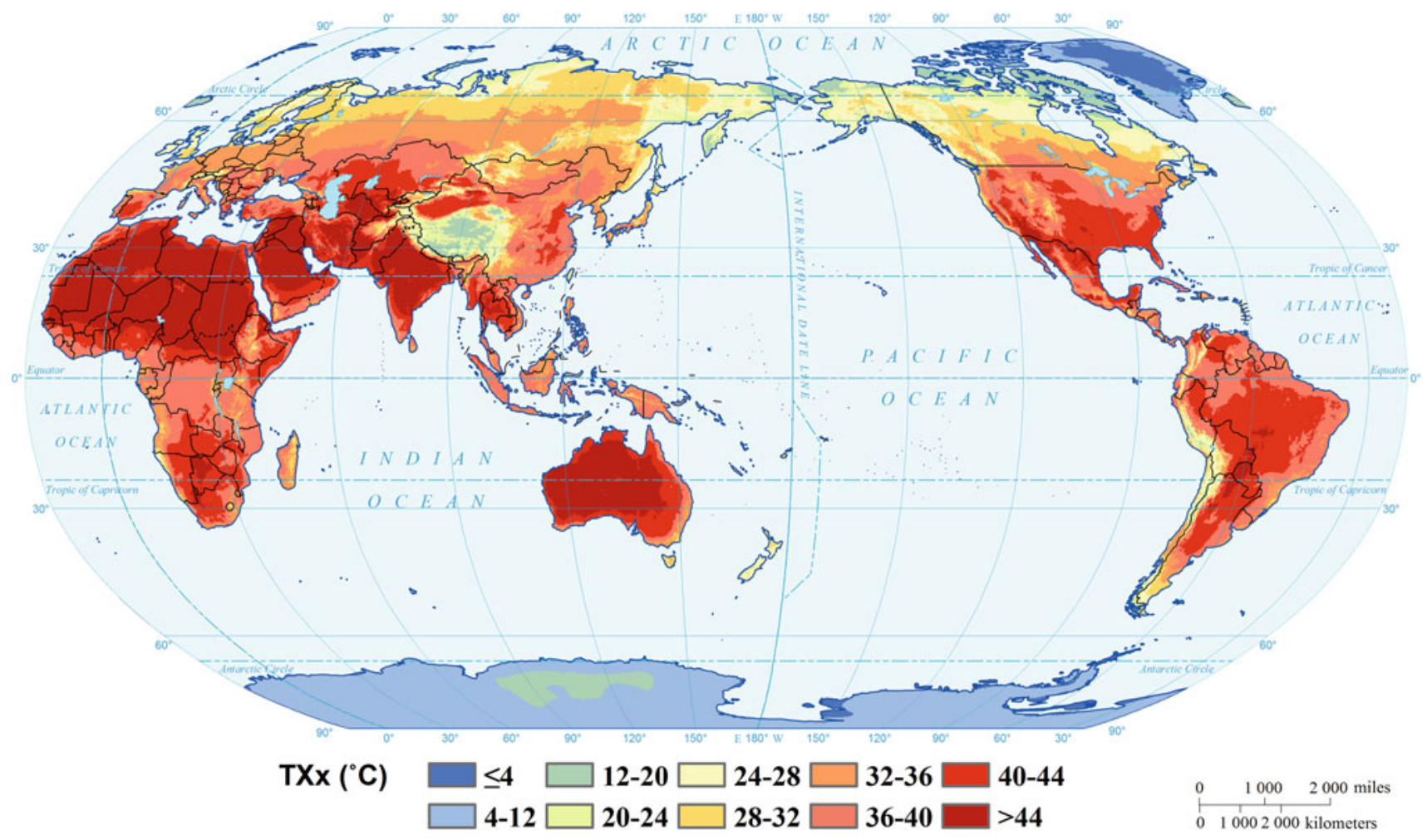




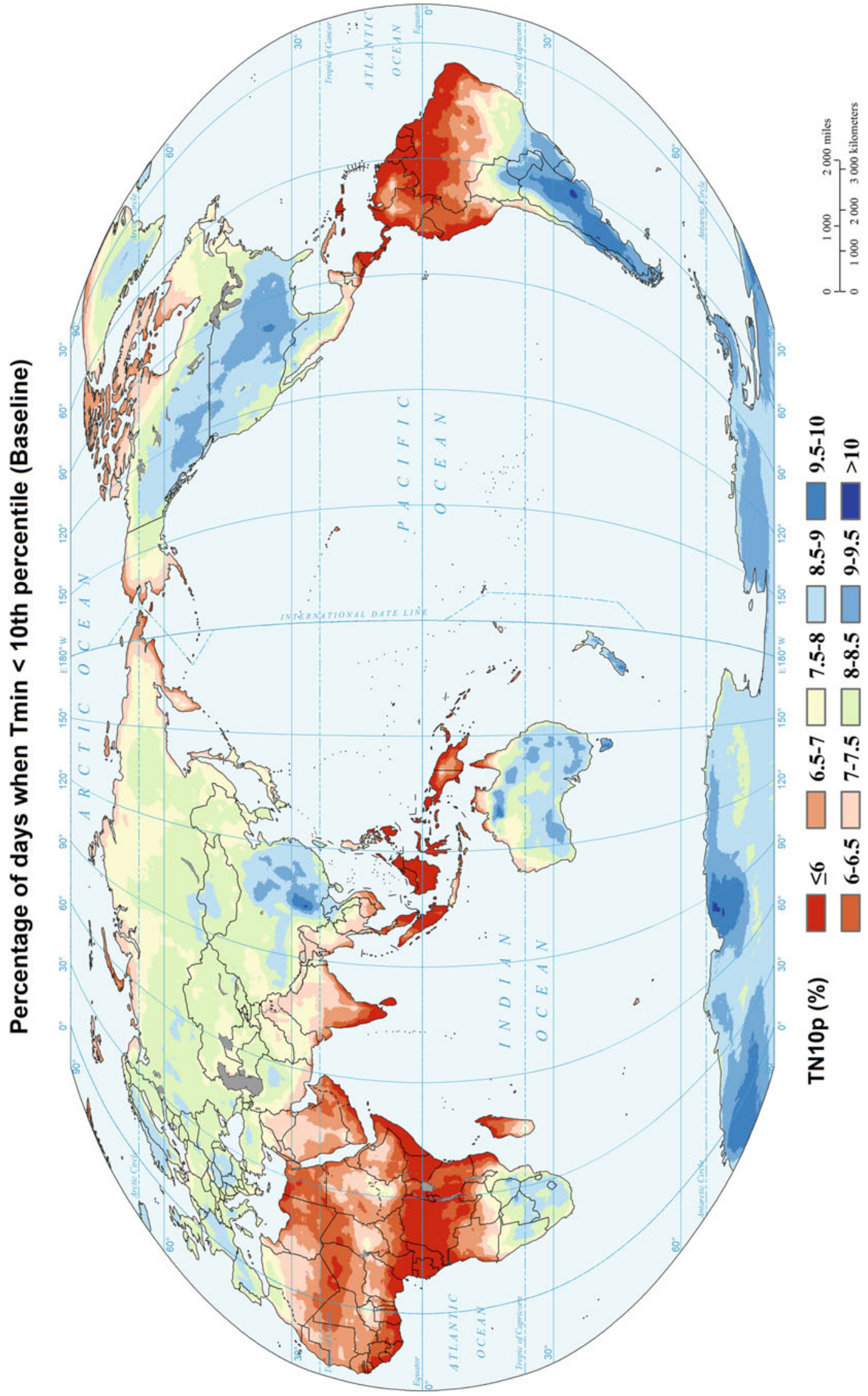


Percentage of days when Tmin < 10th percentile (2030s, RCP2.6)

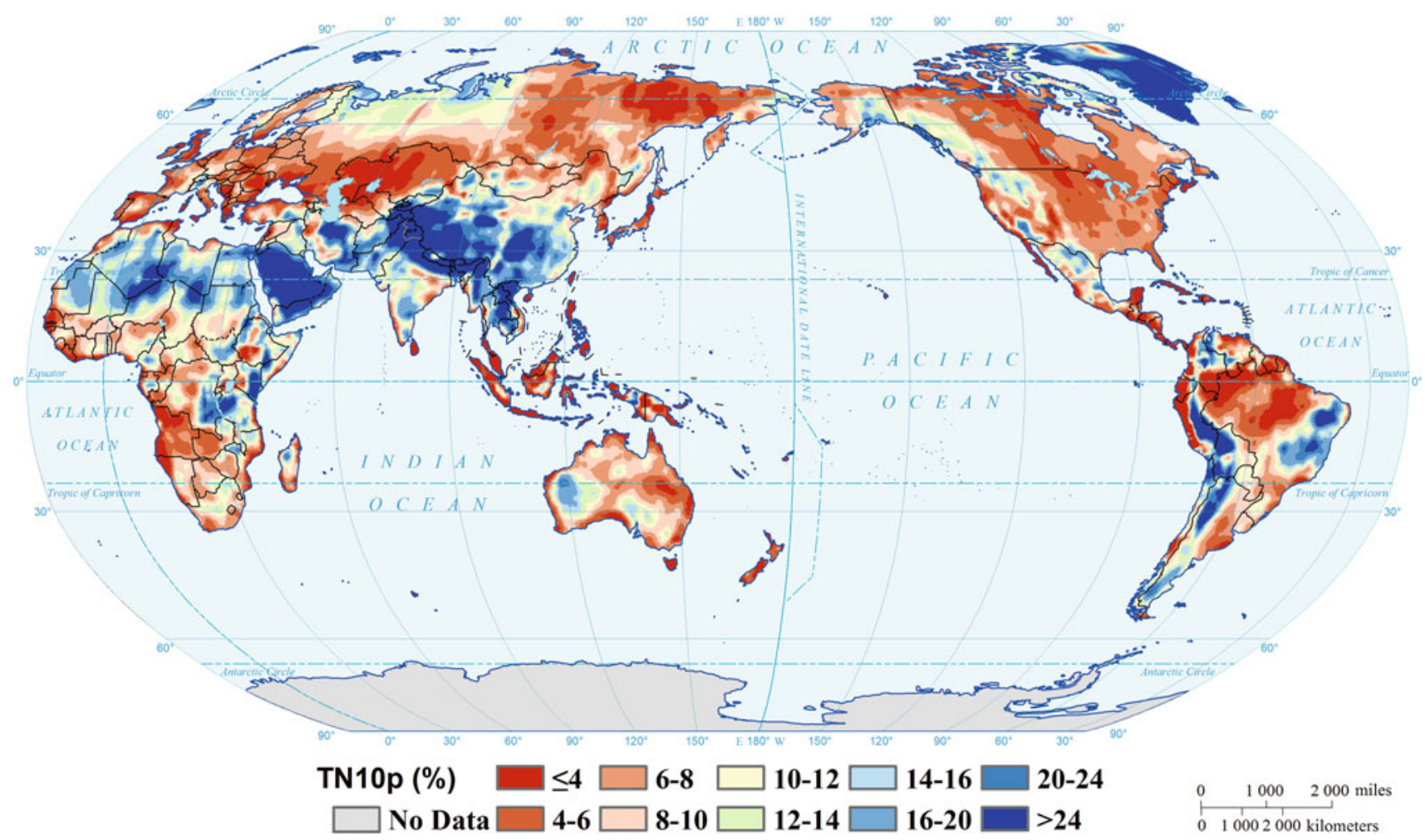

Percentage of days when Tmin < 10th percentile (2030s, RCP4.5)

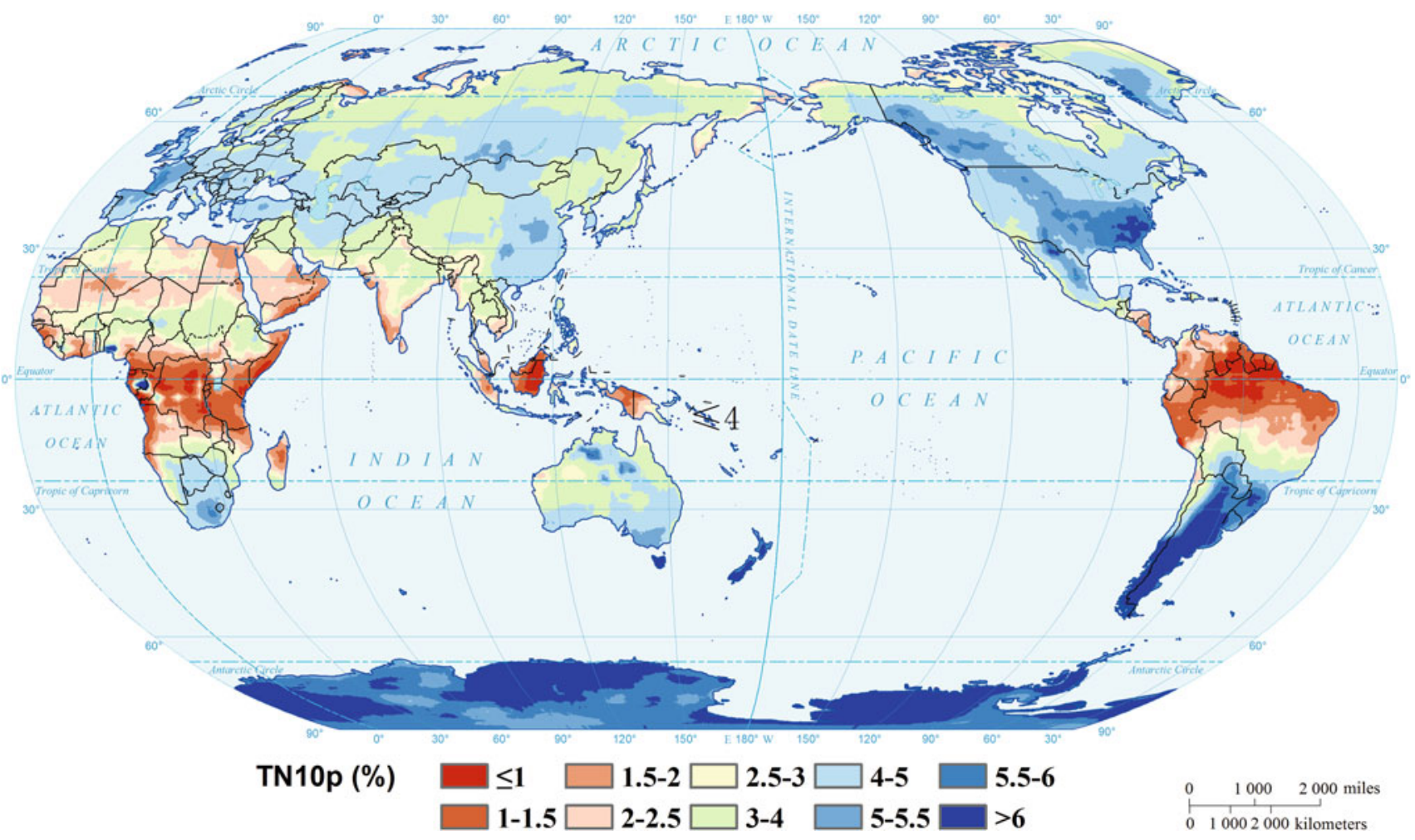


Percentage of days when Tmin < 10th percentile (2030s, RCP8.5)

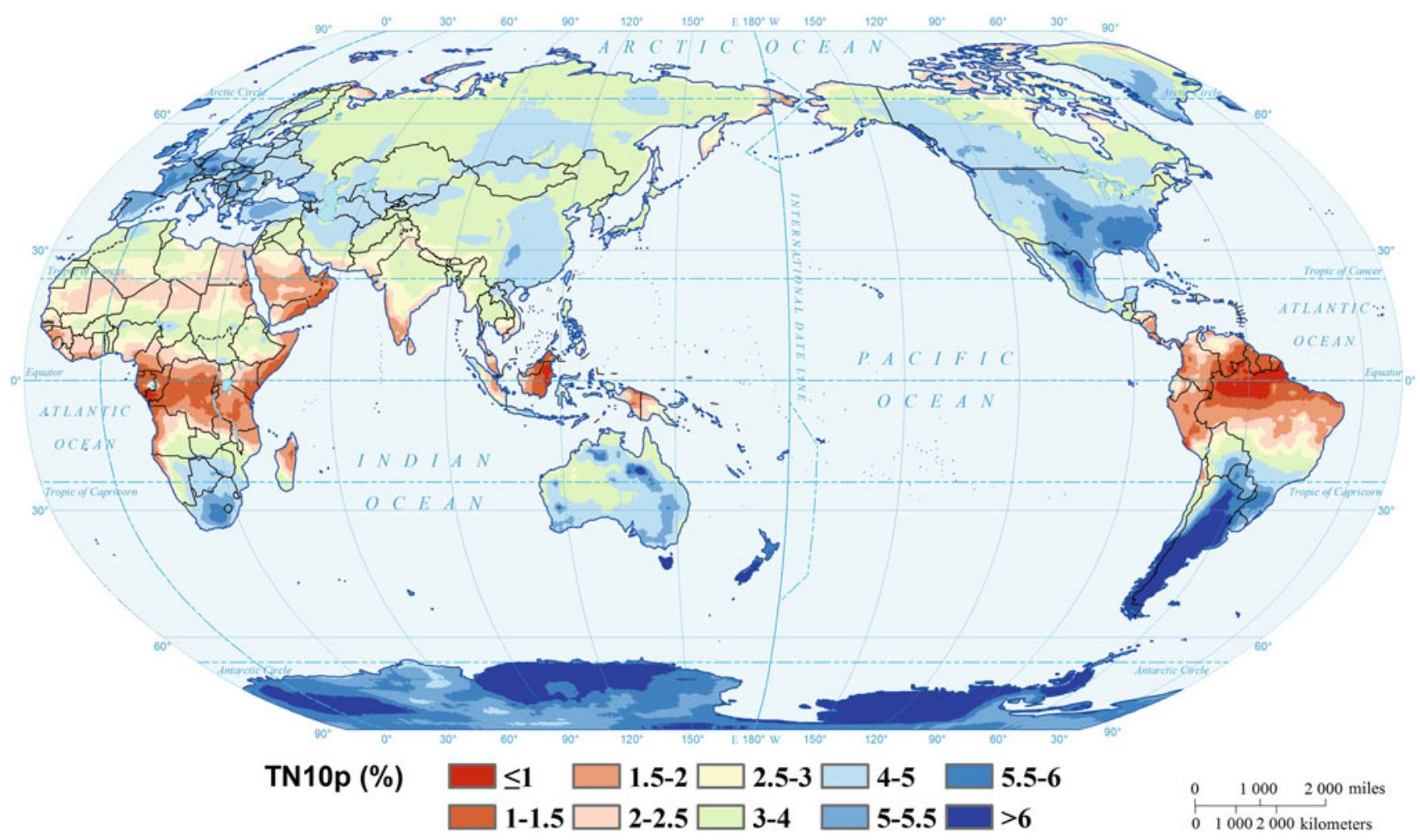

Percentage of days when Tmin < 10th percentile (2050s, RCP2.6)

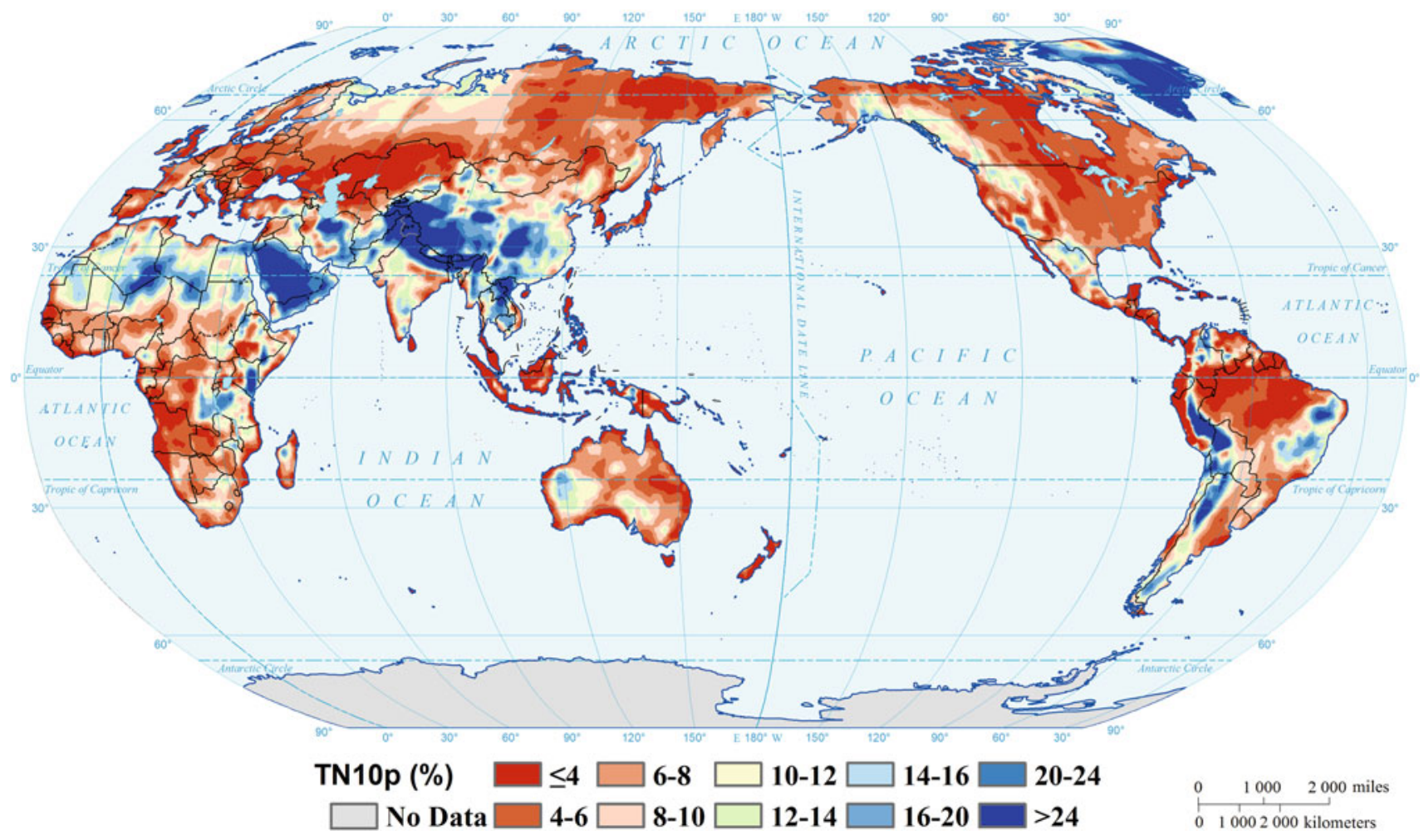


Percentage of days when Tmin < 10th percentile (2050s, RCP4.5)

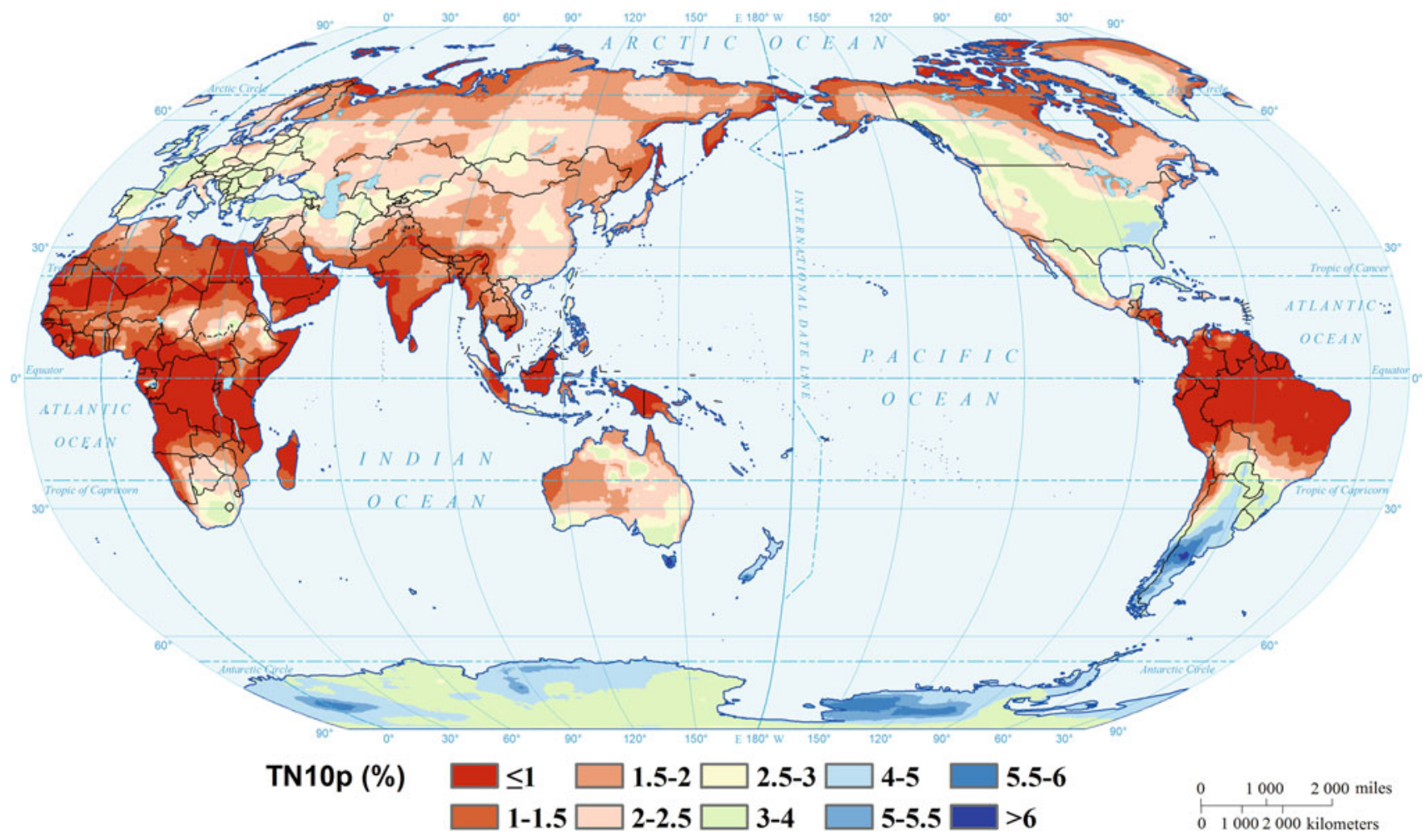

Percentage of days when Tmin < 10th percentile (2050s, RCP8.5)

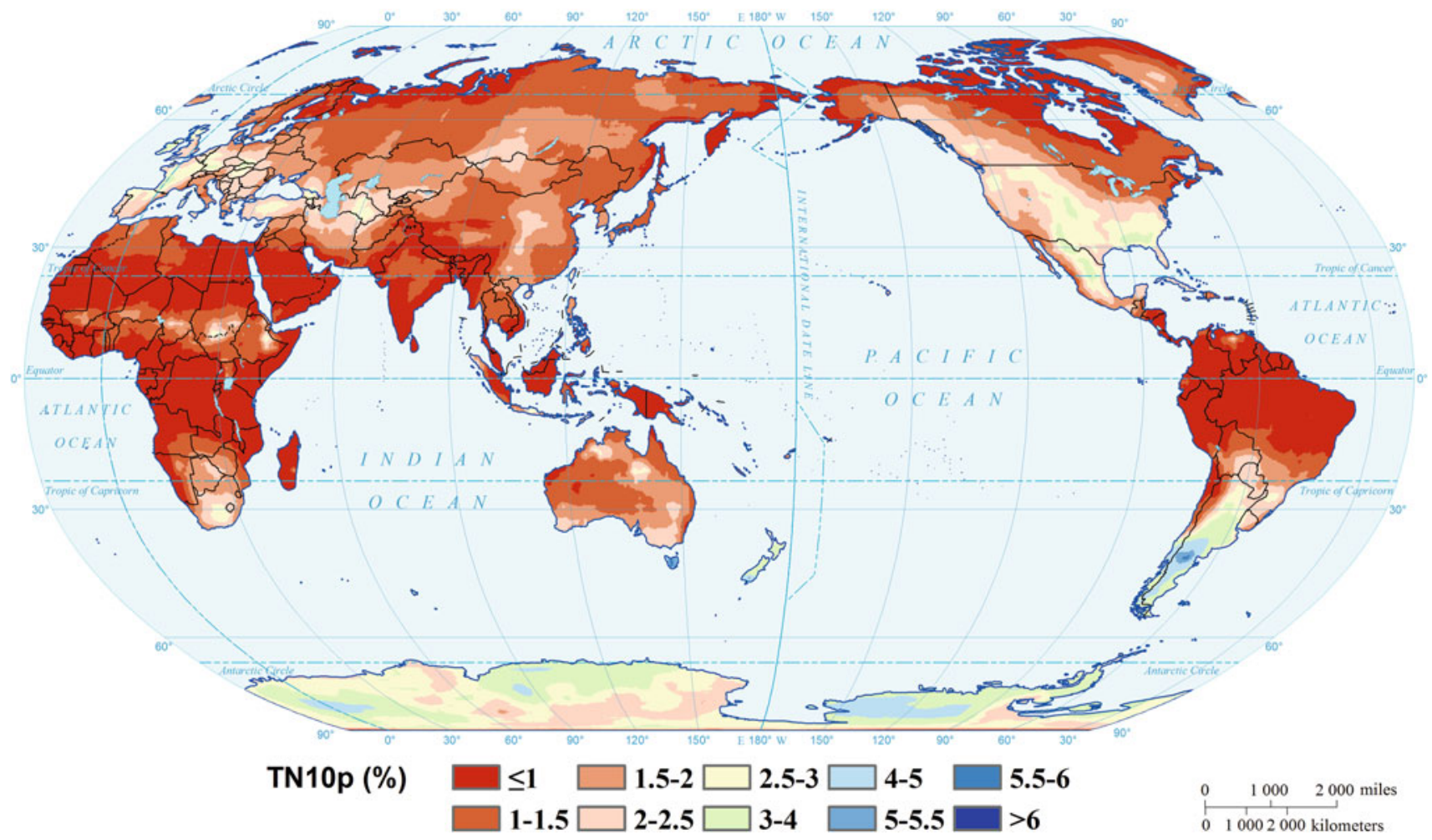




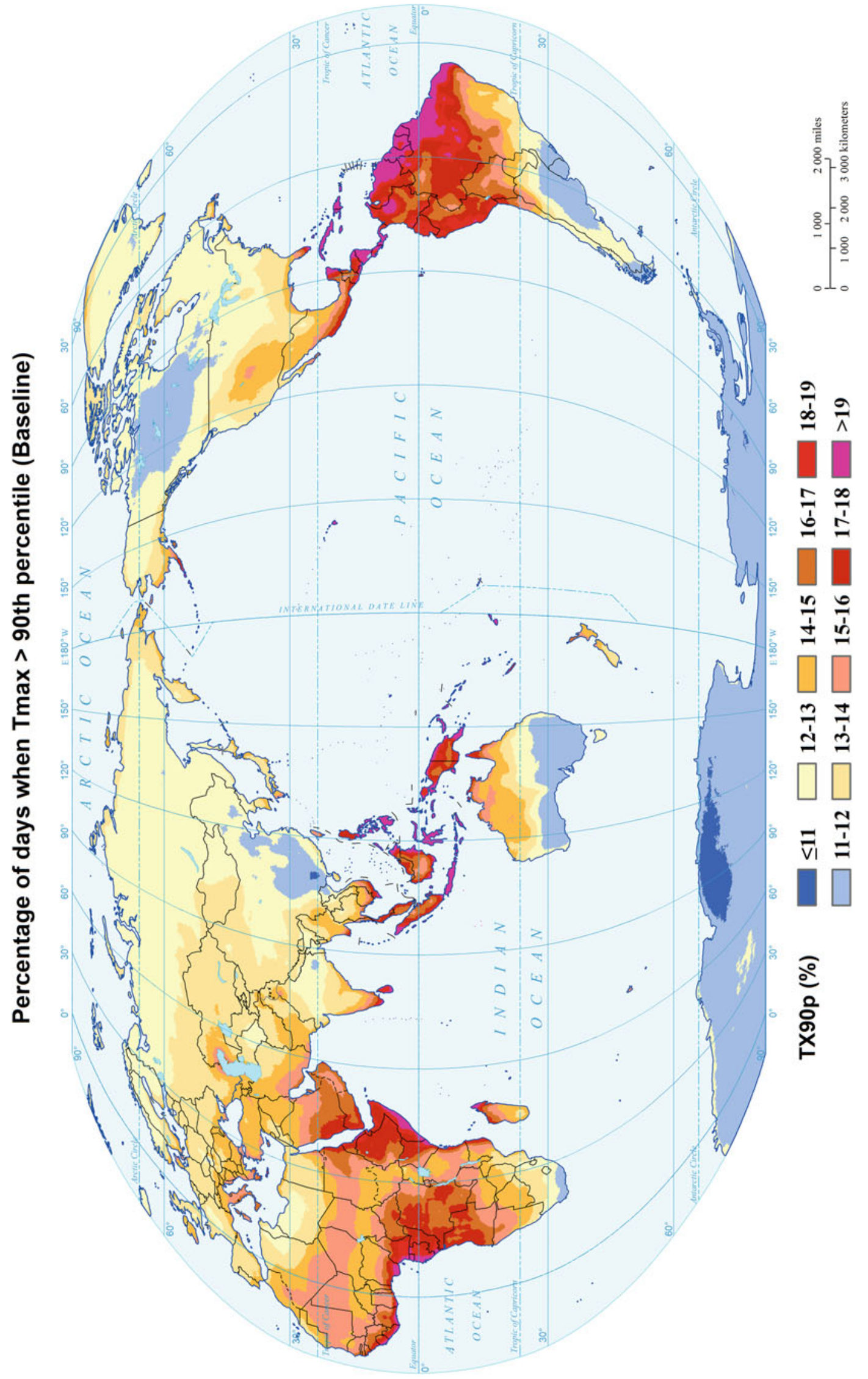


Percentage of days when Tmax > 90th percentile (2030s, RCP2.6)

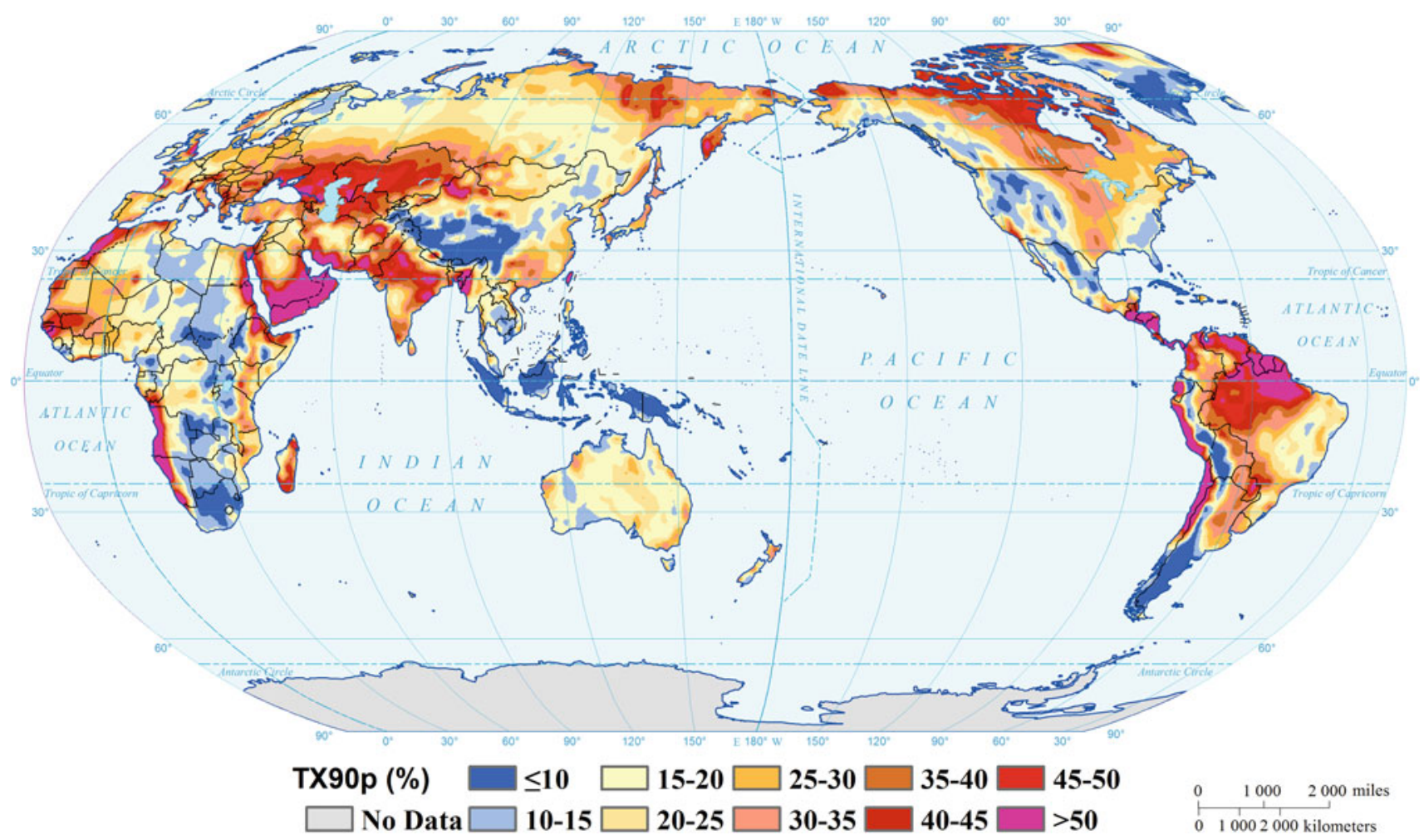

Percentage of days when Tmax > 90th percentile (2030s, RCP4.5)

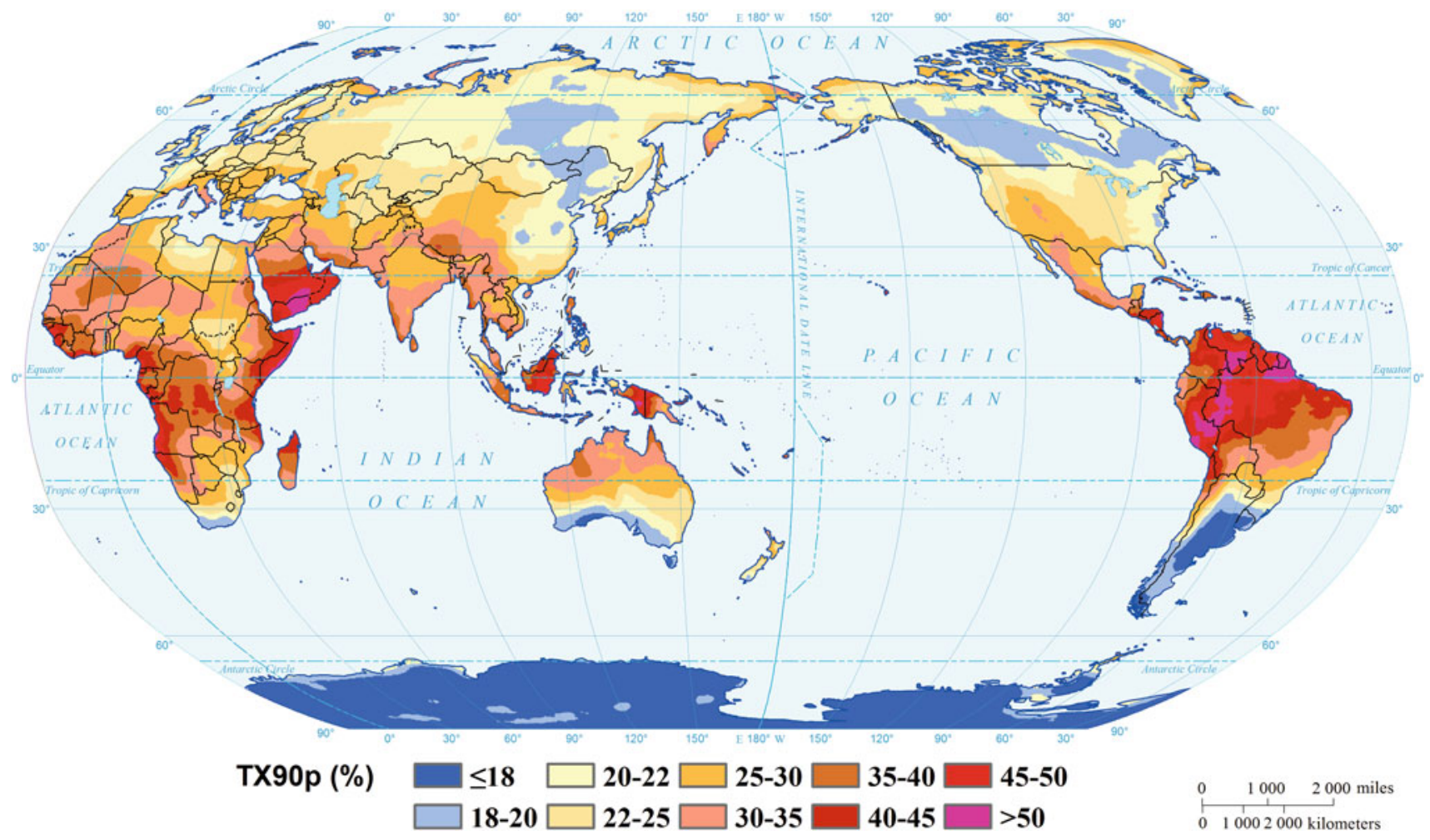


Percentage of days when Tmax > 90th percentile (2030s, RCP8.5)

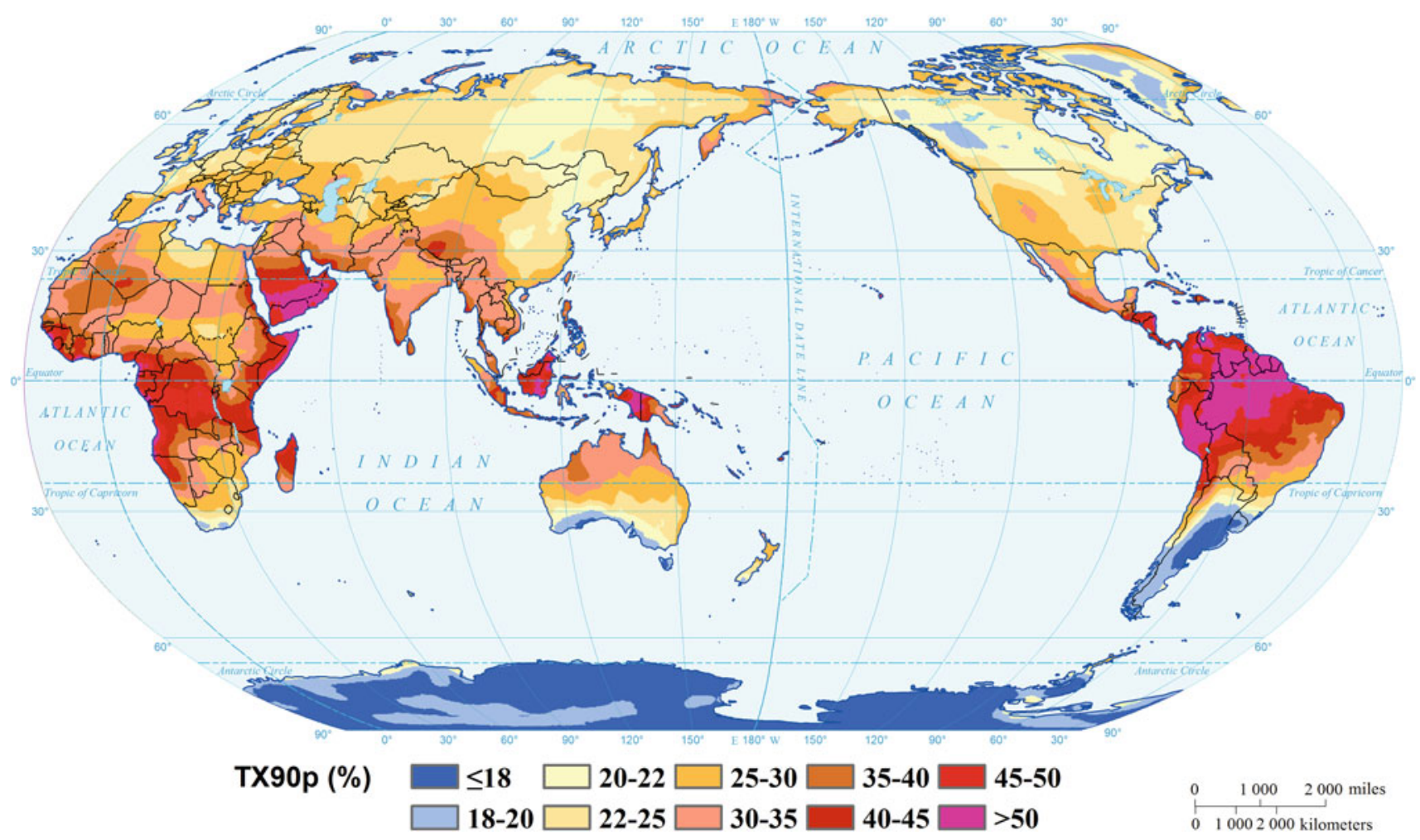

Percentage of days when Tmax > 90th percentile (2050s, RCP2.6)

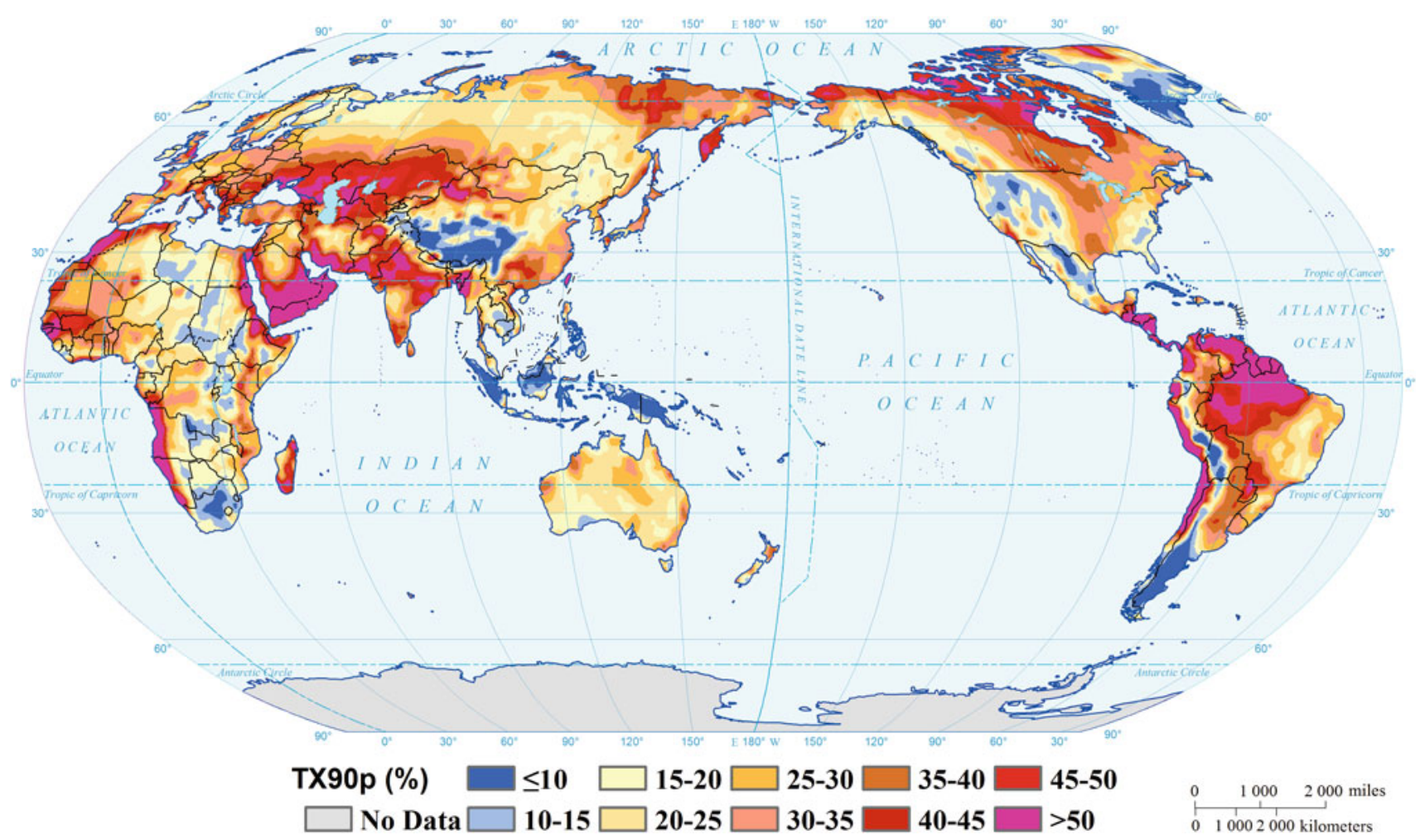


Percentage of days when Tmax > 90th percentile (2050s, RCP4.5)

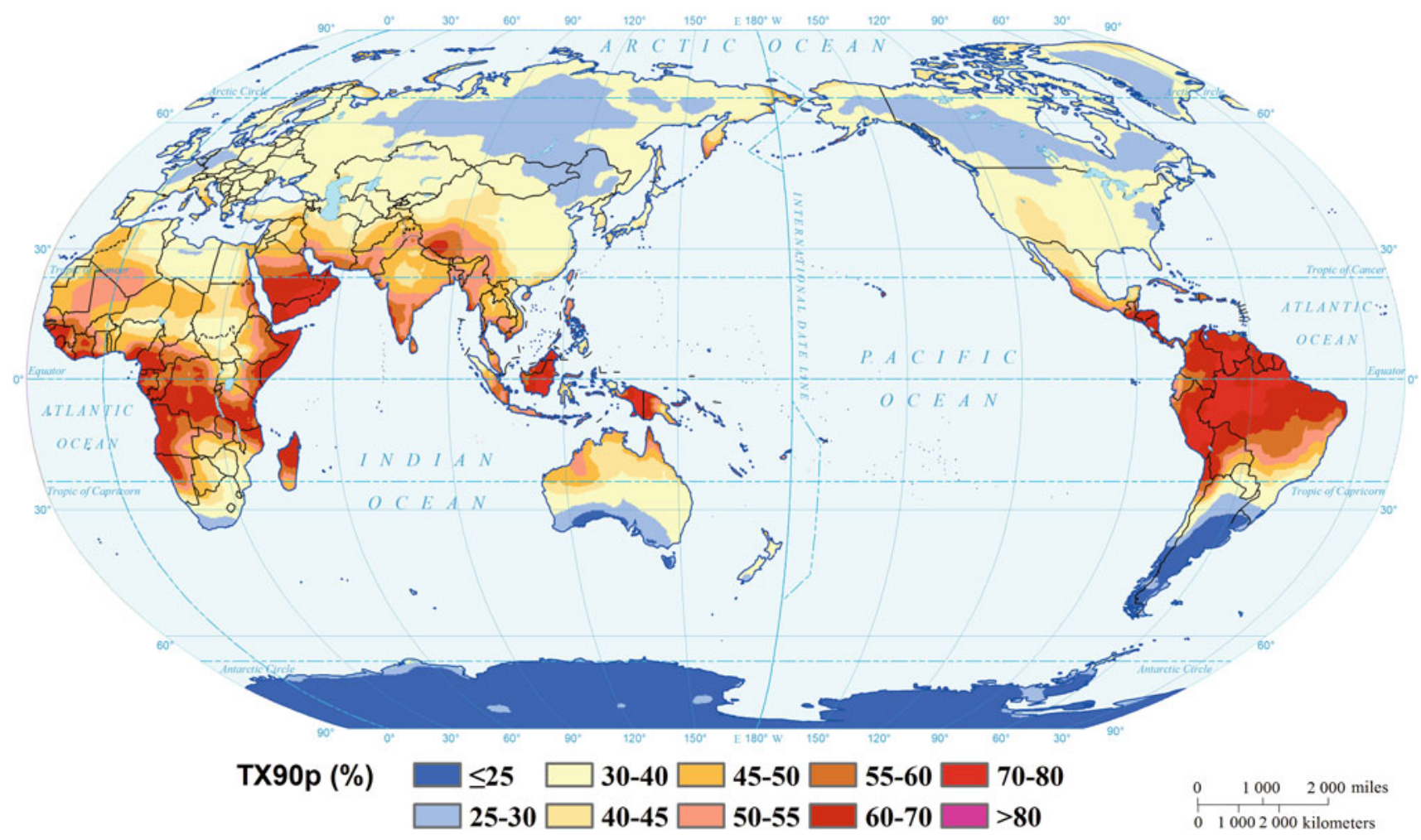

Percentage of days when Tmax > 90th percentile (2050s, RCP8.5)

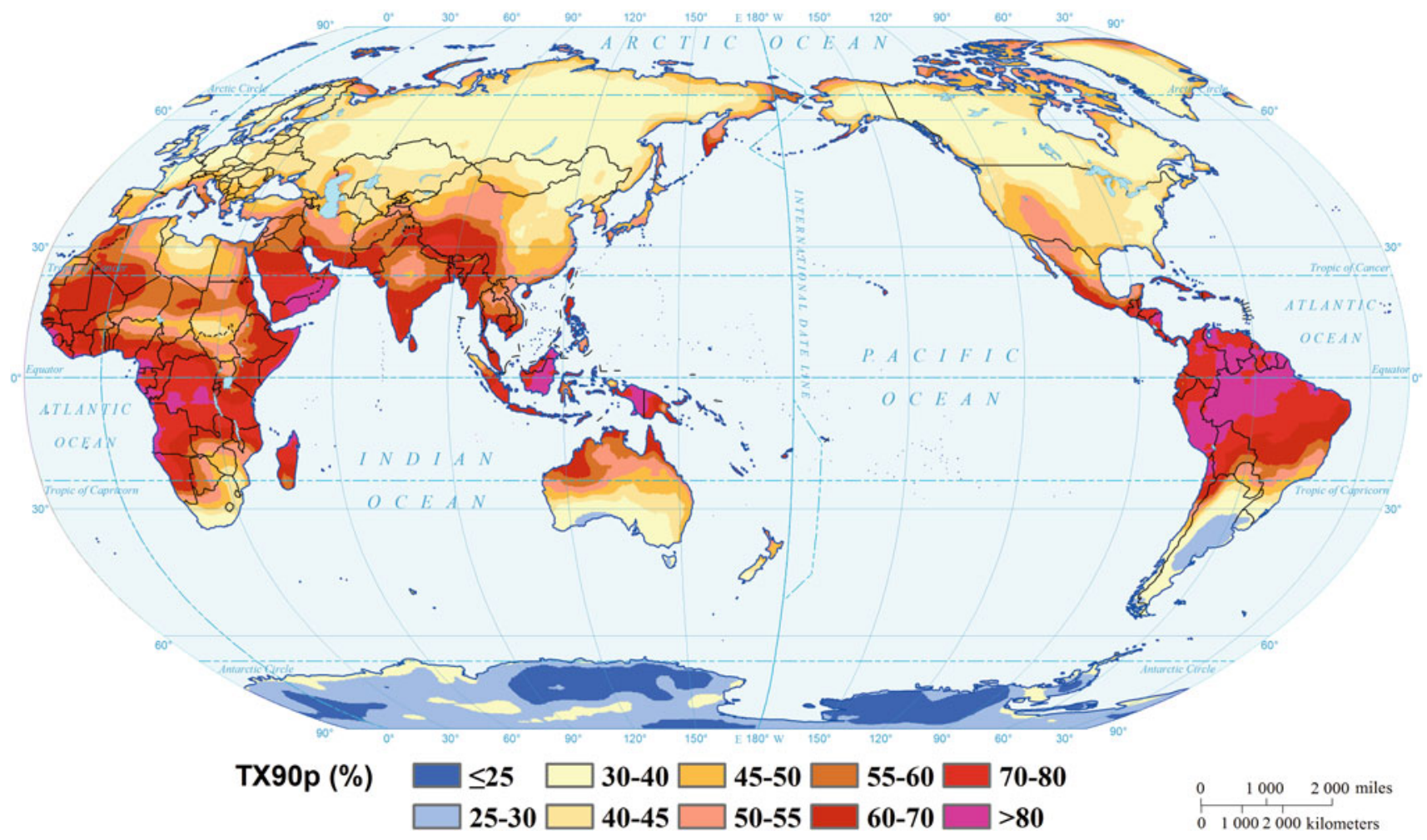




\section{References}

Alexander, L.V., X. Zhang, T.C. Peterson, J. Caesar, B. Gleason, A.M. G. Klein Tank, M. Haylock, D. Collins, et al. 2006. Global observed changes in daily climate extremes of temperature and precipitation. Journal of Geophysical Research: Atmospheres 111 (D5): D05109.

Bao, Y., and X.Y. Wen. 2017. Projection of China's near- and long-term climate in a new high-resolution daily downscaled dataset NEX-GDDP. Journal of Meteorological Research 31 (1): 236-249.

Dosio, A., L. Mentaschi, E.M. Fischer, and K. Wyser. 2018. Extreme heat waves under $1.5{ }^{\circ} \mathrm{C}$ and $2{ }^{\circ} \mathrm{C}$ global warming. Environmental Research Letter 13(5): 54006.

Easterling, D.R., G.A. Meehl, C. Parmesan, S.A. Changnon, T.R. Karl, and L.O. Mearns. 2000. Climate extremes: Observations, modeling, and impacts. Science 289 (5487): 2068-2074.

Fan, X., C. Miao, Q. Duan, C. Shen, and Y. Wu. 2020. The performance of CMIP6 versus CMIP5 in simulating temperature extremes over the global land surface. Journal of Geophysical Research: Atmospheres 125: e2020JD033031.

Fischer, E.M., and R. Knutti. 2014. Detection of spatially aggregated changes in temperature and precipitation extremes. Geophysical Research Letters 41 (2): 547-554.

Gao, M.N., J. Yang, D.Y. Gong, P.J. Shi, Z.G. Han, and S.J. Kim. 2019. Footprints of atlantic multi-decadal oscillation on the low-frequency variation of extreme high temperature in the northern hemisphere. Journal of Climate 32: 791-802.

Giorgi, F., and X. Bi. 2005. Regional changes in surface climate interannual variability for the 21 st century from ensembles of global model simulations. Geophysical Research Letters 32: L13701.

Grumm, R.H. 2011. The Central European and Russian heat event of July-August 2010. Bulletin of the American Meteorological Society 92 (10): 1285-1296.

Karl, T.R., and D.R. Easterling. 1999. Climate extremes: Selected review and future research directions. Climatic Change 42 (1): 309 325.

Luo, Z.Q., J. Yang, M.N. Gao, and D.L. Chen. 2020. Extreme hot days over three global megaregions: Historical fidelity and future projection. Atmospheric Science Letters 21: e1003.

Maurer, E.P., H.G. Hidalgo, T. Das, M.D. Dettinger, and D.R. Cayan. 2010. The utility of daily large-scale climate data in the assessment of climate change impacts on daily streamflow in California. Hydrology and Earth System Sciences 14 (6): 1125-1138.

Nangombe, S., T.J. Zhou, X.W. Zhang, B. Wu, S. Hu, L.W. Zou, and D.H. Li. 2018. Record-breaking climate extremes in Africa under stabilized $1.5{ }^{\circ} \mathrm{C}$ and $2{ }^{\circ} \mathrm{C}$ global warming scenarios. Nature Climate Change 8(5): 375-380.

Piao, S., P. Ciais, Y. Huang, Z. Shen, S. Peng, J. Li, L. Zhou, H. Liu, et al. 2010. The impacts of climate change on water resources and agriculture in China. Nature 467 (7311): 43-51.

Qi, X., J. Yang, M. Gao, H. Yang, and H. Liu. 2019. Roles of the tropical/extratropical intraseasonal oscillations on generating the heat wave over Yangtze River valley: A numerical study. Journal of Geophysical Research: Atmospheres 124: 3110-3123.

Sun, Y., T. Hu, X.B. Zhang, H. Wan, P. Stott, and C.H. Lu. 2018. Anthropogenic influence on the eastern China 2016 super cold surge. Bulletin of the American Meteorological Society 99 (1): S123-127.

Thrasher, B., E.P. Maurer, C. McKellar, and P.B. Duffy. 2012. Technical note: Bias correcting climate model simulated daily temperature extremes with quantile mapping. Hydrology and Earth System Sciences 16 (9): 3309-3314.

Thrasher, B., J. Xiong, W. Wang, F. Melton, A. Michaelis, and R. Nemani. 2013. Downscaled climate projections suitable for resource management. Eos, Transactions American Geophysical Union 94 (37): 321-323.

Wang, Y.J., A.Q. Wang, J.Q. Zhai, H. Tao, T. Jiang, B.D. Su, J. Yang, G.J. Wang, et al. 2019. Tens of thousands additional deaths annually in cities of China between $1.5{ }^{\circ} \mathrm{C}$ and $2.0{ }^{\circ} \mathrm{C}$ warming. Nature Communications 10(1): 3376.

Wood, A.W., L.R. Leung, V. Sridhar, and D.P. Lettenmaier. 2004. Hydrologic implications of dynamical and statistical approaches to downscaling climate model outputs. Climatic Change 62 (1-3): $189-216$.

Xu, L., and A. Wang. 2019. Application of the bias correction and spatial downscaling algorithm on the temperature extremes from CMIP5 multi-model ensembles in China. Earth and Space Science 6 (12): 2508-2524.

Zhang, X., L. Alexander, G.C. Hegerl, P. Jones, A.K. Tank, T.C. Peterson, B. Trewin, and F.W. Zwiers. 2011. Indices for monitoring changes in extremes based on daily temperature and precipitation data. Wires Climate Change 2 (6): 851-870.

Zheng, F., Y. Yuan, Y.H. Ding, K.X. Li, X.H. Fang, Y.H. Zhao, Y. Sun, J. Zhu, et al. 2021. The 2020/21 extremely cold winter in China influenced by the synergistic effect of La Niña and warm Arctic. Advances in Atmospheric Sciences https://doi.org/10.1007/ s00376-021-1033-y.

Zobel, Z., J.L. Wang, D.J. Wuebbles, and V.R. Kotamarthi. 2017. High-resolution dynamical downscaling ensemble projections of future extreme temperature distributions for the United States. Earth's Future 5 (12): 1234-1251.
Open Access This chapter is licensed under the terms of the Creative Commons Attribution 4.0 International License (http:// creativecommons.org/licenses/by/4.0/), which permits use, sharing, adaptation, distribution and reproduction in any medium or format, as long as you give appropriate credit to the original author(s) and the source, provide a link to the Creative Commons license and indicate if changes were made.
The images or other third party material in this chapter are included in the chapter's Creative Commons license, unless indicated otherwise in a credit line to the material. If material is not included in the chapter's Creative Commons license and your intended use is not permitted by statutory regulation or exceeds the permitted use, you will need to obtain permission directly from the copyright holder.

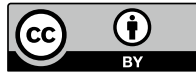

